\title{
Article \\ Channel Strategies for the Two-Period Closed-Loop Supply Chain with E-Commerce
}

\author{
Lin Zhao ${ }^{1}$ and Zongyu $\mathrm{Mu}^{2, *}$ \\ 1 School of International Trade and Economics, University of International Business and Economics, \\ Beijing 100029, China; 202000160016@uibe.edu.cn \\ 2 School of Business, Qingdao University, Qingdao 266071, China \\ * Correspondence: mzydragon@163.com
}

check for

updates

Citation: Zhao, L.; Mu, Z. Channel Strategies for the Two-Period Closed-Loop Supply Chain with E-Commerce. Mathematics 2021, 9, 1271. https://doi.org/10.3390/ math9111271

Academic Editor: Armin Fügenschuh

Received: 17 May 2021

Accepted: 28 May 2021

Published: 1 June 2021

Publisher's Note: MDPI stays neutral with regard to jurisdictional claims in published maps and institutional affiliations.

Copyright: (c) 2021 by the authors. Licensee MDPI, Basel, Switzerland. This article is an open access article distributed under the terms and conditions of the Creative Commons Attribution (CC BY) license (https:// creativecommons.org/licenses/by/ $4.0 /)$.

\begin{abstract}
The aim of this paper is to choose the effective selling channel and reverse channel for a closed-loop supply chain (CLSC) with the e-commerce. The authors formulated six single-selling and dual-selling channel two-period CLSC models in which the manufacturer manufactures new products in the first period and then collects used products by itself, outsourcing to or cooperating with the retailer in the second period. Some interesting and new insights obtained from comparison analysis and numerical experiments are as follows: (1) The leading manufacturer ought to add e-commerce channel, and customers' e-commerce preference can increase the market demand, collecting rate, and manufacturer's profit. (2) With the e-commerce channel and the retail channel, dual-collecting channel is the best for the manufacturer and system while the manufacturer collecting channel becomes the best when the collecting competition is relatively large. When the collecting competition exists, retailer collecting channel is the best for the retailer. (3) The market demand, collecting rate, the profits of all members and system will rise by increasing the remanufacturing level and discount coefficient.
\end{abstract}

Keywords: selling and reverse channel; closed-loop supply chain; e-commerce; two-period game

\section{Introduction}

The shortening life cycle and rapid technology innovation have greatly accelerated the updating speed of products in terms of function and appearance, leading to a sharp growth of such wastes as electronic devices, household appliances, and plastics [1]. How to reduce the harmful impacts of product wastes, such as carbon emissions and environmental pollution, has been widely concerned by countries all over the world. More and more enterprises, such as Apple, Canon, Boeing, and Caterpillar, pay increasing attention to recycling and remanufacturing their used products by operating CLSC for a long time, which not only helps them to increase profits and enhance competitiveness but also enables them to maximize resource utilization and build positive social image [2]. Particularly, Minnesota Mining and Manufacturing (3M) is a "pollution prevention" visionary pioneer and "sustainable development" advocate. Because the "end-of pipe" pollution control cost much and achieve little, 3M proposed the "Pollution Prevention Pays (PPP)" project, which saves billions of dollars in costs and is an all-win approach for itself, the environment, the society, the consumers, and even the workers in the company. Moreover, due to the rising awareness of environmental protection, more and more consumers have a stronger willingness to purchase recyclable products, which enables enterprises to expand market shares and obtain more profits.

The key problem for operating CLSC is to recycle used products with effective reverse channel [3]. In practice, there are three ways by which used products can be returned from consumers. In terms of direct reverse channel for self-recovery, Xerox recycles the used copiers by prepaid mailing boxes to remanufacture, which enables it to save about $40-65 \%$ of producing costs and receive a hundred-million dollars. In terms of an indirect reverse 
channel for outsourcing the retailer, Kodak recycles throw-away cameras from its retailers, who are paid with fixed fees per camera. As for dual reverse channel for self-recovery and outsourcing the retailer, Apple not only recycles used electronic products from its retailers but also from consumers who send their used electronic products back to Apple, according to the prepaid shipping label generated by going to Apple's official website; Adidas and Dell cooperate with their respective raw material suppliers; Coca-Cola ties up with the third-party recycler. However, it has been proven by many studies that the effective reverse channel varies under different business conditions [3-9].

In today's competitive business environment, approximately $68 \%$ of manufacturers in a variety of industries redesign their forward supply chain configuration through ecommerce [10]. Many enterprises, such as IBM, HP, Panasonic, Cisco System, Huawei, and Nike, have established a dual-channel selling mode, which is an integration of burgeoning e-commerce channel and traditional retail channel [11-15]. Specially, Dell, which is known for its success in e-commerce mode, announced that it would build an e-commerce channel to take the advantage of both channels and to stimulate the market demands. Apple, the largest information technology company in the world, has 478 retail stores across 17 countries and operates the online App Store simultaneously. The e-commerce channel not only gives consumers lower price, unconstrained shopping time and location, various products, and efficient express delivery but also allows manufacturers to reduce trade costs and benefit from the expanded market segments [16], as well as enhance control over retail price [11]. Meanwhile, the e-commerce channel is playing an important role in consumption markets. According to Forrester's latest five years' e-commerce forecast, the value of online sales was $\$ 297$ billion in 2014 in the U.S., and it would grow up to $\$ 480$ billion by 2019 [17]. “The Monitoring Report of China's Online Retail Market Data in 2017" reported that the online market scale reached $\$ 1.07$ trillion in China, which increased by $39.17 \%$ compared with the previous year and constituted $19.6 \%$ of the total sales. As e-commerce channel and retail channel sell the same products and have a competitive relationship, the structure design of CLSC with dual-selling channel has become an urgent problem. Nevertheless, to the best of our knowledge, few studies have analyzed the reverse channel design problem of CLSC considering e-commerce.

For the above industrial observation and considering that the return process of CLSC is inherently dynamic, a two-period CLSC operating system with e-commerce is proposed in this paper. In this system, the manufacturer is assumed to manufacture new products made from raw materials in the first period, manufacture new products made from raw materials and remanufacture products made from used products in the second period. The authors also characterize the discount profits in the subsequent period. This paper formulates direct reverse channel, indirect reverse channel, and dual reverse channel two-period CLSC models considering single- and dual-selling modes, respectively. Further, the paper aims to shed light on the following problems: (1) Which is the best reverse channel structure for every member in three single-channel models? (2) Should the manufacturer open dual-channel with e-commerce technology? (3) Which is the best reverse channel structure for every member in three dual-channel models? (4) How do customers' e-commerce preference, product remanufacturing level and discount coefficient affect pricing decisions, remanufacturing behaviors, every member's profit, and channel strategy?

The rest arrangement of this paper is as follows. The literature related to the study is reviewed in Section 2; relevant assumptions are presented in Section 3; the formulated models and its equilibrium decisions are discussed in Section 4; numerical experiments are performed in Section 5 for providing more interesting illustrations; conclusions and limitations are presented in Section 6.

\section{Literature Review}

This paper is closely related to three research streams. The first stream is the literature that examines the optimal reverse channel strategy, which can be divided into two lines. The first line is to consider single-collecting channel. For example, Savaskan et al. 
studied three models, including the manufacturer collecting, the retailer collecting, and the third-party collecting and found that the retailer collecting is the optimal reverse channel structure [3]. Savaskan and Wassenhove extended [3] to consider competing retailers. They found that the optimal is driven by the scale of returns on collection efforts with the manufacturer-collecting channel, yet it is driven by competition among the retailers with the retailer collecting channel [4]. Wu and Zhou explored the manufacturer collecting and the retailer collecting models with two competing CLSCs. They found that the retailer collecting always leads to a higher return rate [18]. Atasu et al. considered the manufacturer collecting and the retailer collecting models with different collection cost structure. They demonstrated that the manufacturer collecting is the optimal method with diseconomies of scale, while the retailer collecting is the optimal method with economies of scale [7]. Hong et al. considered the centralized collection; the decentralized collection, including the retailer collecting; the manufacturer collecting; and the third-party collecting, taking into account the retailer's local advertising. They found that the retailer collecting is the optimal for the manufacturer [19]. Miao et al. considered the centralized collection and decentralized collection models with trade-ins and showed that the centralized collection is better than the decentralized collection, the manufacturer collecting is better than the retailer collecting for the manufacturer and system, and the retailer collecting is better than the manufacturer collecting for the retailer and environment [20]. Wang et al. examined the collecting rejection, self-collecting, and outsourcing-collecting models and demonstrated that collecting and remanufacturing used products is always beneficial to the manufacturer, and the reverse channel strategy depends on the cost of self-collecting or the compensation of outsourcing collecting [21]. Modak et al. studied three models, including the manufacturer collecting, the retailer collecting, and the third-party collecting, taking into account price and product quality dependent on demand. They demonstrated that the third-party collecting is always negative [22]. The second line is to consider dualcollecting channel. For example, Liu et al. studied the manufacturer- and retailer collecting model, the retailer- and third-party collecting model, and the manufacturer- and third-party collecting model and found that the manufacturer- and retailer collecting is the optimal method for the manufacturer [23]. Zhao et al., respectively, explored the manufacturer- and retailer collecting and the manufacturer- and third-party collecting models. They revealed that dual-collecting channel is better than single-collecting channel. Again, it is always beneficial for the retailer to participate in collection [24]. The above studies considered the CLSC with a single-period model. Some papers extended these studies to consider the reverse channel strategy with a two-period model. In single-collecting channel, Giovanni and Zaccour considered a two-period CLSC and found that the retailer- or third-party collecting is the optimal only when the retailer or third-party has a better operational and environmental performance than the manufacturer. Further, the retailer collecting is the optimal only when the retailer and third-party have an equal operational performance [25]. In dual-collecting channel, Mondal et al. explored a two-period CLSC with greening level and effort-dependent demand and found that dual-collection is the optimal for the supply chain [26].

The second stream is the literature that examines the selling channel strategy with ecommerce. For example, Chiang et al. examined the effect of demand share for e-commerce channel on selling channel design. They found that e-commerce channel is beneficial to the manufacturer and may not always be detrimental to the retailer [11]. Lu and Liu found that e-commerce channel is always positive for the retailer, but it is positive for the manufacturer only when demand share for the retail channel is below a certain threshold or the e-commerce channel is sufficiently competitive [27]. Zhang et al. studied selling channel design from the perspective of the retailer and found that the optimal structures are single retail channel, dual-channel, and single e-commerce channel when demand share for the e-commerce channel varies from low to medium to high [28]. Chen et al. explored the impact of selling channels, including single retail channel, single e-commerce channel, and dual-channel. They revealed that dual-channel is beneficial to the manufacturer, but 
it depends on quality coefficient and channel substitutability for the retailer [29]. Li et al. examined the impact of different pricing strategies on selling channel design, taking into account quality-differentiated products. They found that the manufacturer and the retailer are always benefited from dual-channel under uniform pricing strategy. Again, the manufacturer is benefited from dual-channel only when demand share of e-commerce channel is low; the retailer does not benefit from dual-channel under PPS [30]. Saha et al. explored single-channel and dual-channel in three-echelon supply chain and found that dual-channel is not certainly better than single channel. Further, the retailer prefers the retailer's dual-channel and single-channel, and the distributor prefers the retailer's dualchannel [31]. Pun et al. examined the impact of consumers' freeriding for presales service on the manufacturer's channel design and found that the manufacturer prefers the retail channel [32].

The third stream is the literature that examines CLSC with e-commerce. This research stream can be divided into two lines; the first line is to consider the optimal selling channel strategy. For example, He et al. examined the carbon emissions problem with consumer freeriding in a dual-channel CLSC and showed that the manufacturer would be cautious about opening dual-channel, as consumer freeriding has a negative impact on the environment [33]. Batarfi et al. studied the selling channel design with different return policies and found that dual-channel is better than single-channel [34]. Taleizadeh et al. examined the selling channel design in a dual-collecting CLSC. They demonstrated that dual-channel is better for the manufacturer, that the retailer's channel design depends on the demand share for e-commerce channel, and that dual-channel and single-channel are the same to the third-party [35]. He et al. examined a dual-channel CLSC with government subsidy, taking into account no direct sales (D); selling new product directly but selling remanufactured product via the third-party $(\mathrm{MN})$; and selling remanufactured product directly but selling new product via the retailer (MR). They found that, in the case of moderate cost saving from remanufacturing, both the government and the manufacturer prefer $\mathrm{MN}$ when environmental impact discount is high; otherwise, they prefer MR. Again, government always advocates MR [36]. Xiao et al. studied the optimal channel structure with trade-in and found that the retailer prefers dual-channel when customers' acceptance for direct channel exceeds a certain threshold; the manufacturer prefers dual-channel when customers' acceptance for direct channel is within a certain range [37]. Shi et al. studied the selling channel strategy and found that a decentralized firm benefits from the indirect channel; a centralized firm benefits from direct channel [38]. The second line is to consider the optimal reverse channel strategy. For example, Saha et al. studied the manufacturer collecting model, the retailer collecting model, and the third-party collecting model under reward-driven remanufacturing policy, taking into account e-commerce. They found that the manufacturer collecting is the optimal method for the manufacturer and system, and the retailer collecting is the optimal method for the retailer and consumers. Further, remanufacturing rate of the manufacturer collecting is the highest [8]. Li et al. studied four return strategies and found that the manufacturer prefers full refund in both channels when the collecting rate is low and otherwise prefers no refund in both channels. Again, the retailer prefers full refund in the retail channel only when the collecting rate is low, and otherwise prefers full refund in e-commerce channel [39].

As compared with the above literatures, the fundamental differences of the paper lie in that (i) the authors consider the selling channel and reverse channel strategy simultaneously, and (ii) the authors assume that the supply chain is operated under two-period environment and incorporate the dynamic changes of product-life period and enterprise's discount profits over the time. Thus, to operate closed-loop supply chain with e-commerce more effectively and realistically, this paper formulates direct reverse channel, indirect reverse channel, and dual reverse channel two-period CLSC models, taking into account the singleand dual-selling modes, respectively, to study the optimal selling and reverse channel strategy. The literature positioning of this paper is presented in Table 1. 
Table 1. Representative literatures positioning of this paper.

\begin{tabular}{|c|c|c|c|c|c|c|c|}
\hline & \multirow{2}{*}{ CLSC } & \multicolumn{2}{|c|}{ Reverse Channel Strategy } & \multirow{2}{*}{ E-Commerce } & \multirow{2}{*}{ Selling Channel Strategy } & \multicolumn{2}{|c|}{ Environment } \\
\hline & & Single-Collecting & Dual-Collecting & & & Single-Period & Two-Period \\
\hline Savaskan et al. [3] & $\checkmark$ & $\checkmark$ & - & - & - & $\checkmark$ & - \\
\hline Savaskan et al. [4] & $\checkmark$ & $\checkmark$ & - & - & - & $\checkmark$ & - \\
\hline Wu et al. [18] & $\checkmark$ & $\checkmark$ & - & - & - & $\checkmark$ & - \\
\hline Atasu et al. [7] & $\checkmark$ & $\checkmark$ & - & - & - & $\checkmark$ & - \\
\hline Hong et al. [19] & $\checkmark$ & $\checkmark$ & - & - & - & $\checkmark$ & - \\
\hline Miao et al. [20] & $\checkmark$ & $\checkmark$ & - & - & - & $\checkmark$ & - \\
\hline Wang et al. [21] & $\checkmark$ & $\checkmark$ & - & - & - & $\checkmark$ & - \\
\hline Modak et al. [22] & $\checkmark$ & $\checkmark$ & - & - & - & $\checkmark$ & - \\
\hline Liu et al. [23] & $\checkmark$ & $\checkmark$ & - & - & - & $\checkmark$ & - \\
\hline Zhao et al. [24] & $\checkmark$ & $\checkmark$ & - & - & - & $\checkmark$ & - \\
\hline Giovanni et al. [25] & $\checkmark$ & $\checkmark$ & - & - & - & - & $\checkmark$ \\
\hline Mondal et al. [26] & $\checkmark$ & - & $\checkmark$ & - & - & - & $\checkmark$ \\
\hline Chiang et al. [11] & - & - & - & $\checkmark$ & $\checkmark$ & $\checkmark$ & - \\
\hline Lu et al. [27] & - & - & - & $\checkmark$ & $\checkmark$ & $\checkmark$ & - \\
\hline Zhang et al. [28] & - & - & - & $\checkmark$ & $\checkmark$ & $\checkmark$ & - \\
\hline Chen et al. [29] & - & - & - & $\checkmark$ & $\checkmark$ & $\checkmark$ & - \\
\hline Pun et al. [32] & - & - & - & $\checkmark$ & $\checkmark$ & $\checkmark$ & - \\
\hline He et al. [33] & $\checkmark$ & - & - & $\checkmark$ & $\checkmark$ & $\checkmark$ & - \\
\hline Batarfi et al. [34] & $\checkmark$ & - & - & $\checkmark$ & $\checkmark$ & $\checkmark$ & - \\
\hline Taleizadeh et al. [35] & $\checkmark$ & - & - & $\checkmark$ & $\checkmark$ & $\checkmark$ & - \\
\hline He et al. [36] & $\checkmark$ & - & - & $\checkmark$ & $\checkmark$ & $\checkmark$ & - \\
\hline Xiao et al. [37] & $\checkmark$ & - & - & $\checkmark$ & $\checkmark$ & $\checkmark$ & - \\
\hline Shi et al. [38] & $\checkmark$ & - & - & $\checkmark$ & $\checkmark$ & $\checkmark$ & - \\
\hline Saha et al. [8] & $\checkmark$ & $\checkmark$ & - & $\checkmark$ & - & $\checkmark$ & - \\
\hline Li et al. [39] & $\checkmark$ & $\checkmark$ & - & $\checkmark$ & - & $\checkmark$ & - \\
\hline This study & $\checkmark$ & - & $\checkmark$ & $\checkmark$ & $\checkmark$ & - & $\checkmark$ \\
\hline
\end{tabular}




\section{Problem Description}

To investigate the manufacturer's selling channel and reverse channel design, this paper proposes a two-player CLSC with two consecutive selling periods. In the first period, new products made from raw materials are manufactured and sold by single-channel (i.e., to the retailer via retail channel) or by dual-channel (i.e., both to consumers via e-commerce channel and to the retailer via retail channel). In the second period, used products need to be collected, which are sold in the first period and, thus, have a residual value, and the collection can be realized through three CLSC configurations: direct reverse channel (collecting by the manufacturer), indirect reverse channel (collecting by the retailer), and dual reverse channel (collecting by the manufacturer and the retailer). New products can satisfy consumers' utility only in one selling period, and remanufactured products are homogenous with consumer utility. The sequence of events is shown in Figure 1. Based on various reverse channels, this paper further formulates three single-channel models, as shown in Figure 2, and three dual-channel models, as shown in Figure 3. The key parameters and detailed definitions throughout this paper are given in Table 2.

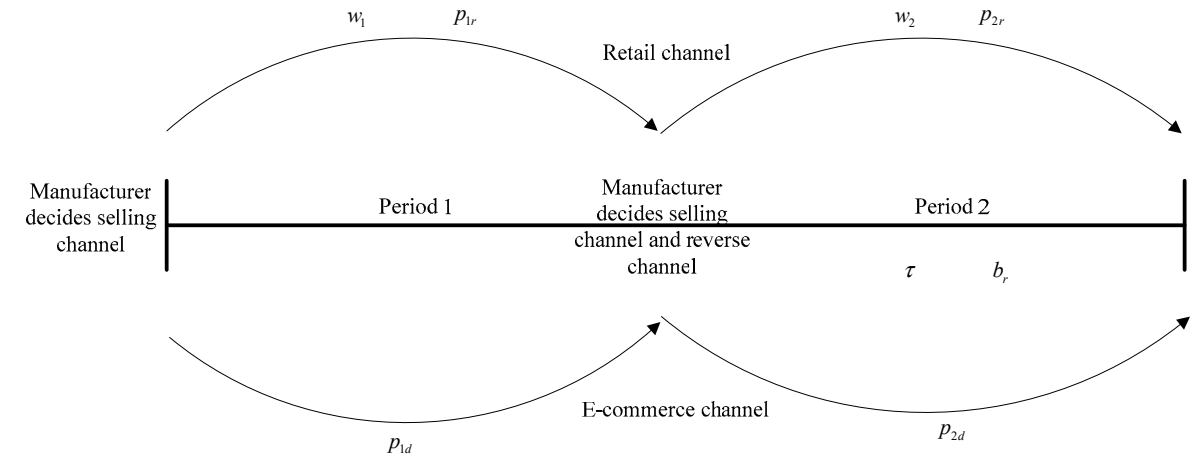

Figure 1. The sequence of events.

Assumption 1. The decision-making processes follow Stackelberg game [40-42]. That is, the manufacturer is the leader, and the retailer is the follower.

Assumption 2. Savaskan et al. and Huang et al. showed that the market demand and the selling price have a linear relationship [3,43]. In the single-channel systems, the demand function is $D_{k}=a-\beta p_{k}, k=1,2$. In the dual-channel systems, the demand function of retail channel is $D_{k r}=\rho a-\beta p_{k r}+\gamma p_{k d}, k=1,2$; the demand function of e-commerce channel is $D_{k d}=$ $(1-\rho) a-\beta p_{k d}+\gamma p_{k r}, k=1,2 ; \beta>\gamma$ means that the sensitivity coefficient for self-price is larger than that for cross-price [44,45].

Assumption 3. Similar to [3], when the manufacturer or the retailer collects used products independently, the collecting cost function is defined as $C=C_{L} \tau_{i}{ }^{2}, i=m, r$; when the manufacturer and the retailer collect used products simultaneously, the collecting cost function is defined as $C_{i}=\frac{C_{L}\left(\alpha \tau_{j}{ }^{2}+\tau_{i}{ }^{2}\right)}{1-\alpha^{2}}, i, j \in\{m, r\}$, which illustrates that each member's collection cost is related to collecting rate of itself and its competitor [43,46,47].

Assumption 4. $C_{L}$ is a scale parameter, which represents the exchanging coefficient between collecting rate and collecting cost and is large enough so as to guarantee the remanufacturing process is sufficiently profitable for the manufacturer [3]. In single-channel systems, $C_{L}$ needs to satisfy the condition $C_{L}>\frac{\left(\Delta-b_{c}\right)\left(a-\beta c_{m}\right)}{4}+\frac{\beta \delta\left(\Delta-b_{c}\right)^{2}}{4}$. In dual-channel systems, $C_{L}$ needs to satisfy the condition $C_{L}>\frac{\left(\Delta-b_{c}\right)\left[a-2 c_{m}(\beta-\gamma)\right]}{4}+\frac{\delta(\beta-\gamma)\left(\Delta-b_{c}\right)^{2}}{2}$.

Assumption 5. To guarantee the profitability of the manufacturer, unit remanufacturing cost for used products must be lower than unit manufacturing cost for new products, i.e., $c_{m}<c_{r}$. 
$\Delta=c_{m}-c_{r}$ is the saving cost for remanufacturing, representing the remanufacturing level, and $\Delta>b_{r}>b_{c}$.

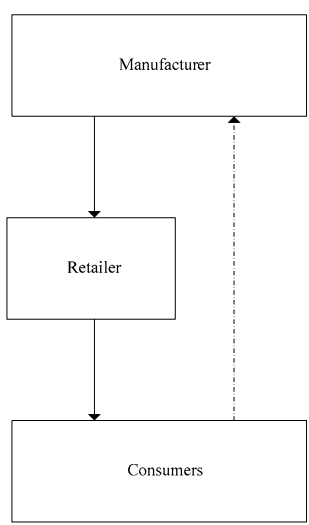

(a) Manufacturer collecting in single-

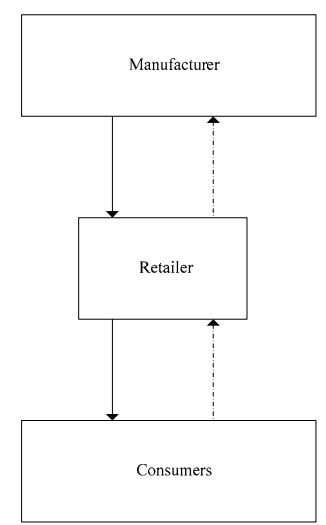

(b) Retailer collecting in single-channel

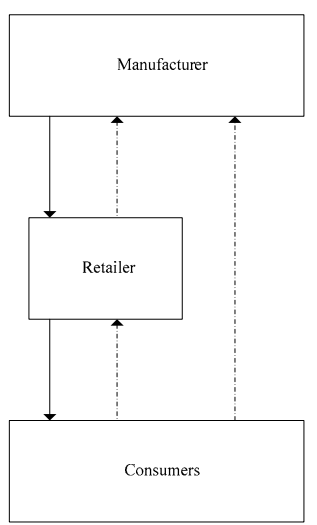

(c) Manufacturer- and Retailer collecting

Figure 2. Three single-channel CLSC models.

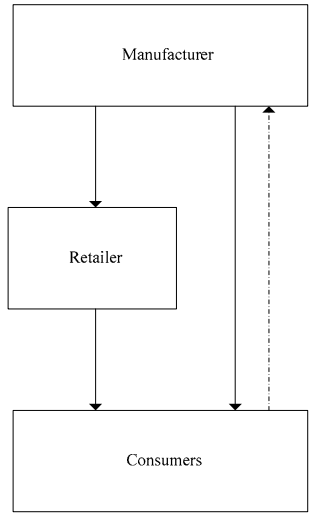

(d) Manufacturer collecting in dualchannel CLSC



(e) Retailer collecting in duatchannel

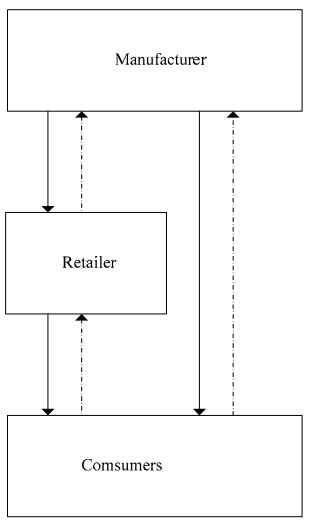

(f) Manufacturer- and Retailer collecting in dual-channel CLSC

Figure 3. Three dual-channel CLSC models.

Table 2. Parameters and definitions.

$w_{k}, k=1,2$
$p_{k r}, k=1,2$
$p_{k d}, k=1,2$
$b_{r}$
$b_{c}$
$\delta$
$\tau_{m}$
$\tau_{r}$
$a$
$\beta$
$\gamma$
$\rho$
$c_{m}$
$c_{r}$
$\alpha$

Unit wholesale price in $k$ period

The retailer's unit selling price in $k$ period The manufacturer's unit selling price in $k$ period

Unit transfer price paid to retailer

Unit collecting price paid to customers The discount coefficient

The manufacturer's collecting rate, $0 \leq \tau_{m} \leq 1$

The retailer's collecting rate, $0 \leq \tau_{r} \leq 1$ Basic market demand

Sensitivity coefficient for self-price

Sensitivity coefficient for cross-price Share of basic demand for retail channel, $0 \leq \rho \leq 1$

Unit manufacturing cost for new products

Unit remanufacturing cost for used products The collecting competition coefficient, $0 \leq \alpha<1$ 


\section{Models and Equilibrium Solutions}

\section{(a) M model (Manufacturer collecting)}

(i) SM model (Manufacturer collecting in single-channel CLSC)

For CLSC with common form, the manufacturer selects the option to collect used products by itself so that it can obtain more benefits. For example, in 1988, Lexmark presented "Rebate Program", which meant that consumers could get certain rebates if they returned used cartridges initiatively. In this subsection, the authors characterize a market scenario: in the first period, new products made from raw materials are manufactured and sold to the retailer; in the second period, used products sold in the previous period are collected by the manufacturer, and new products and remanufactured products made from collected ones are sold to the retailer. Therefore, the manufacturer and the retailer's profit functions are:

$$
\begin{gathered}
\Pi_{m}^{S M}\left(w_{1}, w_{2}, \tau_{m}\right)=\left(w_{1}-c_{m}\right) D_{1}+\delta\left[\left(w_{2}-c_{m}\right) D_{2}+\left(\Delta-b_{c}\right) \tau_{m} D_{1}-C_{L} \tau_{m}^{2}\right] \\
\Pi_{r}^{S M}\left(p_{1}, p_{2}\right)=\left(p_{1}-w_{1}\right) D_{1}+\delta\left(p_{2}-w_{2}\right) D_{2}
\end{gathered}
$$

Proposition 1. In the first period, the manufacturer decides the equilibrium wholesale price as $w_{1}^{S M *}=\frac{a\left[4 C_{L}-\beta \delta\left(\Delta-b_{c}\right)^{2}\right]+4 \beta C_{L} c_{m}}{\beta\left[8 C_{L}-\beta \delta\left(\Delta-b_{c}\right)^{2}\right]}$; the retailer decides the equilibrium selling price as $p_{1}^{S M *}=\frac{a\left[6 C_{L}-\beta \delta\left(\Delta-b_{c}\right)^{2}\right]+2 \beta C_{L} c_{m}}{\beta\left[8 C_{L}-\beta \delta\left(\Delta-b_{c}\right)^{2}\right]}$. In the second period, the manufacturer decides the equilibrium wholesale price as $w_{2}^{S M *}=\frac{a+\beta c_{m}}{2 \beta}$ and the equilibrium collecting rate as $\tau_{m}^{S M *}=\frac{\left(\Delta-b_{c}\right)\left(a-\beta c_{m}\right)}{\left[8 C_{L}-\beta \delta\left(\Delta-b_{c}\right)^{2}\right]^{2}}$; the retailer decides the equilibrium selling price as $p_{2}^{S M *}=\frac{3 a+\beta c_{m}}{4 \beta}$.

(ii) DM model (Manufacturer collecting in dual-channel CLSC)

In this subsection, the authors characterize a market scenario: in the first period, new products made from raw materials are manufactured and sold to consumers and the retailer; in the second period, used products sold in the previous period are collected by the manufacturer, and new products and remanufactured products made from collected ones are sold to consumers and the retailer. Therefore, the manufacturer and the retailer's profit functions are:

$$
\begin{gathered}
\Pi_{m}^{D M}\left(w_{1}, p_{1 d}, w_{2}, p_{2 d}, \tau_{m}\right)=\left(w_{1}-c_{m}\right) D_{1 r}+\left(p_{1 d}-c_{m}\right) D_{1 d}+ \\
\delta\left[\left(w_{2}-c_{m}\right) D_{2 r}+\left(p_{2 d}-c_{m}\right) D_{2 d}+\left(\Delta-b_{c}\right) \tau_{m}\left(D_{1 r}+D_{1 d}\right)-C_{L} \tau_{m}{ }^{2}\right] \\
\Pi_{r}^{D M}\left(p_{1 r}, p_{2 r},\right)=\left(p_{1 r}-w_{1}\right) D_{1 r}+\delta\left(p_{2 r}-w_{2}\right) D_{2 r}
\end{gathered}
$$

Proposition 2. In the first period, the manufacturer decides the equilibrium wholesale price as $w_{1}^{D M *}=\frac{a\left[\Psi_{1}+2 \beta \rho \Psi_{2}(\beta-\gamma)\right]+8 \beta C_{L} c_{m} \Psi_{3}\left(\beta^{2}-\gamma^{2}\right)}{2 \Psi_{3} \Psi_{4}\left(\beta^{2}-\gamma^{2}\right)}$ and the equilibrium selling price as $p_{1 d}^{D M *}=\frac{a\left[\beta \Psi_{5}-2 \rho \Psi_{6}(\beta-\gamma)\right]+8 \beta C_{L} c_{m}\left(\beta^{2}-\gamma^{2}\right)}{2 \Psi_{4}\left(\beta^{2}-\gamma^{2}\right)}$; the retailer decides the equilibrium selling price as $p_{1 r}^{D M *}=\frac{a\left[\Psi_{7}+2 \rho \Psi_{8}(\beta-\gamma)\right]+4 C_{2} c_{m} \Psi_{3}(\beta-\gamma)(\beta+\gamma)^{2}}{2 \Psi_{3} \Psi_{4}\left(\beta^{2}-\gamma^{2}\right)}$. In the second period, the manufacturer decides the equilibrium wholesale price as $w_{2}^{D M *}=\frac{a[\gamma+\rho(\beta-\gamma)]+c_{m}\left(\beta^{2}-\gamma^{2}\right)}{2\left(\beta^{2}-\gamma^{2}\right)}$, the equilibrium collecting rate as $\tau_{m}^{D M *}=\frac{\left(\Delta-b_{c}\right)\left[a[2 \beta-\rho(\beta-\gamma)]-c_{m}(3 \beta+\gamma)(\beta-\gamma)\right]}{\Psi_{4}}$, and the equilibrium selling price as $p_{2 d}^{D M *}=\frac{a[\beta-\rho(\beta-\gamma)]+c_{m}\left(\beta^{2}-\gamma^{2}\right)}{2\left(\beta^{2}-\gamma^{2}\right)}$; the retailer decides the equilibrium selling price as

$$
p_{2 r}^{D M *}=\frac{a[2 \beta \gamma+\rho(\beta-\gamma)(3 \beta+\gamma)]+c_{m}(\beta+\gamma)^{2}(\beta-\gamma)}{4 \beta\left(\beta^{2}-\gamma^{2}\right)} .
$$


where $\Psi_{1}, \Psi_{2}, \Psi_{3}, \Psi_{4}, \Psi_{5}, \Psi_{6}, \Psi_{7}$, and $\Psi_{8}$ are constants defined in Appendix A.

\section{(b) $R$ model (Retailer collecting)}

(i) SR model (Retailer collecting in single-channel CLSC)

Because the retailer is closer to consumers, the retailer may achieve the higher collection rate than the manufacturer. For example, ReCellular, as the largest cell phone remanufacturer in the USA, selects to collect used phones from cellular airtime providers. In this subsection, the authors characterize a market scenario: in the first period, new products made from raw materials are manufactured and sold to the retailer; in the second period, used products sold in previous period are collected by the retailer, and then new products and remanufactured products made from collected ones are sold to the retailer. Therefore, the manufacturer and the retailer's profit functions are:

$$
\begin{gathered}
\Pi_{m}^{S R}\left(w_{1}, w_{2}, b_{r}\right)=\left(w_{1}-c_{m}\right) D_{1}+\delta\left[\left(w_{2}-c_{m}\right) D_{2}+\left(\Delta-b_{r}\right) \tau_{r} D_{1}\right] \\
\Pi_{r}^{S R}\left(p_{1}, p_{2}, \tau_{r}\right)=\left(p_{1}-w_{1}\right) D_{1}+\delta\left[\left(p_{2}-w_{2}\right) D_{2}+\left(b_{r}-b_{c}\right) \tau_{r} D_{1}-C_{L} \tau_{r}^{2}\right]
\end{gathered}
$$

Proposition 3. In the first period, the manufacturer decides the equilibrium wholesale price as $w_{1}^{S R *}=\frac{a\left[16 C_{L}-3 \beta \delta\left(\Delta-b_{c}\right)^{2}\right]+\beta c_{m}\left[16 C_{L}-\beta \delta\left(\Delta-b_{c}\right)^{2}\right]}{4 \beta\left[8 C_{L}-\beta \delta\left(\Delta-b_{c}\right)^{2}\right]}$; the retailer decides the equilibrium selling price as $p_{1}^{S R *}=\frac{a\left[6 C_{L}-\beta \delta\left(\Delta-b_{c}\right)^{2}\right]+2 C_{L} \beta c_{m}}{\beta\left[8 C_{L}-\beta \delta\left(\Delta-b_{c}\right)^{2}\right]}$. In the second period, the manufacturer decides the equilibrium wholesale price as $w_{2}^{S R *}=\frac{a+\beta c_{m}}{2 \beta}$ and the equilibrium transfer price asb ${ }_{r}^{S R *}=\frac{\Delta+b_{c}}{2}$; the retailer decides the equilibrium selling price as $p_{2}^{S R *}=\frac{3 a+\beta c_{m}}{4 \beta}$ and the equilibrium collecting rate as $\tau_{r}^{S R *}=\frac{\left(a-\beta c_{m}\right)\left(\Delta-b_{c}\right)}{2\left[8 C_{L}-\beta \delta\left(\Delta-b_{c}\right)^{2}\right]}$.

(ii) DR model (Retailer collecting in dual-channel CLSC)

In this subsection, the authors characterize a market scenario: in the first period, new products made from raw materials are manufactured and sold to consumers and the retailer; in the second period, used products sold in previous period are collected by the retailer, and new products and remanufactured products made from collected ones are sold to consumers and the retailer. Therefore, the manufacturer and the retailer's profit functions are:

$$
\begin{gathered}
\Pi_{m}^{D R}\left(w_{1}, p_{1 d}, w_{2}, p_{2 d}, b_{r}\right)=\left(w_{1}-c_{m}\right) D_{1 r}+\left(p_{1 d}-c_{m}\right) D_{1 d}+ \\
\delta\left[\left(w_{2}-c_{m}\right) D_{2 r}+\left(p_{2 d}-c_{m}\right) D_{2 d}+\left(\Delta-b_{r}\right) \tau_{r}\left(D_{1 r}+D_{1 d}\right)\right] \\
\Pi_{r}^{D R}\left(p_{1 r}, p_{2 r}, \tau_{r}\right)=\left(p_{1 r}-w_{1}\right) D_{1 r}+\delta\left[\left(p_{2 r}-w_{2}\right) D_{2 r}+\left(b_{r}-b_{c}\right) \tau_{r}\left(D_{1 r}+D_{1 d}\right)-C_{L} \tau_{r}^{2}\right]
\end{gathered}
$$

Proposition 4. In the first period, the manufacturer decides the equilibrium wholesale price as $w_{1}^{D R *}=\frac{a\left[\beta \Omega_{1}+\rho \Omega_{2}(\beta-\gamma)\right]+32 \beta C_{L} c_{m} \Omega_{3}\left(\beta^{2}-\gamma^{2}\right)}{\Psi_{3} \Omega_{4}\left(\beta^{2}-\gamma^{2}\right)}$ and the equilibrium selling price as $p_{1 d}^{D R *}=\frac{a\left[\beta \Omega_{5}-\rho \Omega_{6}(\beta-\gamma)\right]+8 \beta C_{L} c_{m} \Omega_{7}\left(\beta^{2}-\gamma^{2}\right)}{\Omega_{4}\left(\beta^{2}-\gamma^{2}\right)}$; the retailer decides the equilibrium selling price as $p_{1 r}^{D R *}=\frac{a\left[\Omega_{8}+\rho \Omega_{9}(\beta-\gamma)\right]+8 \beta C_{L} c_{m} \Omega_{10}\left(\beta^{2}-\gamma^{2}\right)}{\Psi_{3} \Omega_{4} \Omega_{14}\left(\beta^{2}-\gamma^{2}\right)}$. In the second period, the manufacturer decides the equilibrium wholesale price as $w_{2}^{D R *}=\frac{a[\gamma+\rho(\beta-\gamma)]+c_{m}\left(\beta^{2}-\gamma^{2}\right)}{2\left(\beta^{2}-\gamma^{2}\right)}$, the equilibrium selling price as $p_{2 d}^{D R *}=\frac{a[\beta-\rho(\beta-\gamma)]+c_{m}\left(\beta^{2}-\gamma^{2}\right)}{2\left(\beta^{2}-\gamma^{2}\right)}$, and the equilibrium transfer price as $b_{r}^{D R *}=\frac{\Delta+b_{c}}{2}$; the re- 
tailer decides the equilibrium selling price as $p_{2 r}^{D R *}=\frac{a[2 \beta \gamma+\rho(\beta-\gamma)(3 \beta+\gamma)]+c_{m}(\beta-\gamma)(\beta+\gamma)^{2}}{4 \beta\left(\beta^{2}-\gamma^{2}\right)}$ and the equilibrium collecting rate as

$$
\tau_{r}^{D R *}=\frac{2 \beta\left(\beta^{2}-\gamma^{2}\right)\left(\Delta-b_{c}\right)\left[a\left[\Omega_{11}-2 \rho(\beta-\gamma) \Omega_{12}\right]-16 C_{L} c_{m} \Omega_{13}(3 \beta+\gamma)(\beta-\gamma)\right]}{\Psi_{3} \Omega_{4} \Omega_{14}} .
$$

where $\Omega_{1}, \Omega_{2}, \Omega_{3}, \Omega_{4}, \Omega_{5}, \Omega_{6}, \Omega_{7}, \Omega_{8}, \Omega_{9}, \Omega_{10}, \Omega_{11}, \Omega_{12}, \Omega_{13}$, and $\Omega_{14}$ are constants defined in Appendix A.

\section{(c) MR model (Manufacturer- and Retailer collecting)}

(i) SMR model (Manufacturer- and Retailer collecting in single-channel CLSC)

In practice, the manufacturer may add another reverse channel, which will further result in channel competition. For example, HP not only directly provides prepaid mailing boxes to consumers but also subcontracts its retailer with a trade-in policy. In this subsection, the authors characterize a market scenario: in the first period, new products made from raw materials are manufactured and sold to the retailer; in the second period, used products sold in the previous period are collected by the manufacturer and the retailer, and then new products and remanufactured products made from collected ones are sold to the retailer. Therefore, the manufacturer and the retailer's profit functions are:

$$
\begin{gathered}
\Pi_{m}^{S M R}\left(w_{1}, w_{2}, b_{r}, \tau_{m}\right)=\left(w_{1}-c_{m}\right) D_{1}+\delta\left[\left(w_{2}-c_{m}\right) D_{2}+\left[\left(\Delta-b_{r}\right) \tau_{r}+\left(\Delta-b_{c}\right) \tau_{m}\right] D_{1}-\frac{C_{L}\left(\alpha \tau_{r}^{2}+\tau_{m}^{2}\right)}{1-\alpha^{2}}\right] \\
\Pi_{r}^{S M R}\left(p_{1}, p_{2}, \tau_{r}\right)=\left(p_{1}-w_{1}\right) D_{1}+\delta\left[\left(p_{2}-w_{2}\right) D_{2}+\left(b_{r}-b_{c}\right) \tau_{r} D_{1}-\frac{C_{L}\left(\alpha \tau_{m}{ }^{2}+\tau_{r}^{2}\right)}{1-\alpha^{2}}\right]
\end{gathered}
$$

Proposition 5. In the first period, the manufacturer decides the equilibrium wholesale price as

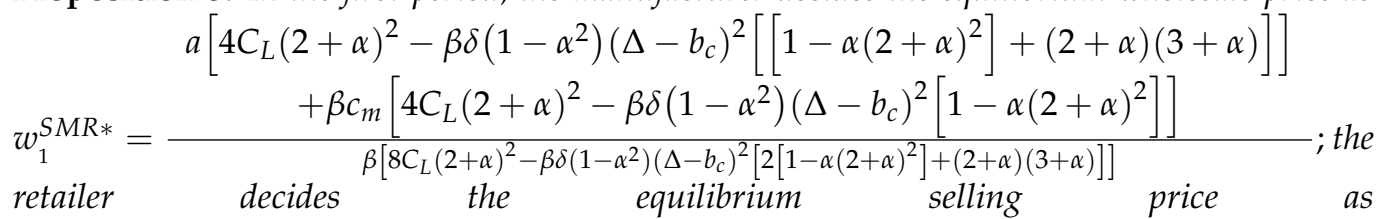
$p_{1}^{S M R *}=\frac{a\left[6 C_{L}(2+\alpha)^{2}-\beta \delta\left(1-\alpha^{2}\right)\left(\Delta-b_{c}\right)^{2}\left[2\left[1-\alpha(2+\alpha)^{2}\right]+(2+\alpha)(3+\alpha)\right]\right]+2 \beta C_{L} c_{m}(2+\alpha)^{2}}{\beta\left[8 C_{L}(2+\alpha)^{2}-\beta \delta\left(1-\alpha^{2}\right)\left(\Delta-b_{c}\right)^{2}\left[2\left[1-\alpha(2+\alpha)^{2}\right]+(2+\alpha)(3+\alpha)\right]\right]}$. In the second period, the manufacturer decides the equilibrium wholesale price as $w_{2}^{S M R *}=\frac{a+\beta c_{m}}{2 \beta}$, the equilibrium collecting rate as $\tau_{m}^{S M R *}=\frac{\left(1-\alpha^{2}\right)(2+\alpha)^{2}\left(\Delta-b_{c}\right)\left(a-\beta c_{m}\right)}{\left[8 C_{L}(2+\alpha)^{2}-\beta \delta\left(1-\alpha^{2}\right)\left(\Delta-b_{c}\right)^{2}\left[2\left[1-\alpha(2+\alpha)^{2}\right]+(2+\alpha)(3+\alpha)\right]\right]}$, and the equilibrium transfer price as $b_{r}^{S M R *}=\frac{\Delta+(1+\alpha) b_{c}}{(2+\alpha)}$; the retailer decides the equilibrium selling price as $p_{2}^{S M R *}=\frac{3 a+\beta c_{m}}{4 \beta}$ and the equilibrium collecting rate as $\tau_{r}^{S M R *}=\frac{\left(1-\alpha^{2}\right)(2+\alpha)\left(\Delta-b_{c}\right)\left(a-\beta c_{m}\right)}{\left[8 C_{L}(2+\alpha)^{2}-\beta \delta\left(1-\alpha^{2}\right)\left(\Delta-b_{c}\right)^{2}\left[2\left[1-\alpha(2+\alpha)^{2}\right]+(2+\alpha)(3+\alpha)\right]\right]}$.

(ii) DMR model (Manufacturer- and Retailer collecting in dual-channel CLSC)

In this subsection, the authors characterize a market scenario: in the first period, new products made from raw materials are manufactured and sold to consumers and the retailer; in the second period, used products sold in the previous period are collected by the manufacturer and the retailer, and new products and remanufactured products made from collected ones are sold to consumers and the retailer. Therefore, the manufacturer and the retailer's profit functions are: 


$$
\begin{gathered}
\Pi_{m}^{D M R}\left(w_{1}, p_{1 d}, w_{2}, p_{2 d}, b_{r}, \tau_{m}\right)=\left(w_{1}-c_{m}\right) D_{1 r}+\left(p_{1 d}-c_{m}\right) D_{1 d}+ \\
\delta\left[\left(w_{2}-c_{m}\right) D_{2 r}+\left(p_{2 d}-c_{m}\right) D_{2 d}+\left[\left(\Delta-b_{r}\right) \tau_{r}+\left(\Delta-b_{c}\right) \tau_{m}\right]\left(D_{1 r}+D_{1 d}\right)-\frac{C_{L}\left(\alpha \tau_{r}{ }^{2}+\tau_{m}{ }^{2}\right)}{1-\alpha^{2}}\right] \\
\Pi_{r}^{D M R}\left(p_{1 r}, p_{2 r}, \tau_{r}\right)=\left(p_{1 r}-w_{1}\right) D_{1 r}+\delta\left[\left(p_{2 r}-w_{2}\right) D_{2 r}+\left(b_{r}-b_{c}\right) \tau_{r}\left(D_{1 r}+D_{1 d}\right)-\frac{C_{L}\left(\alpha \tau_{m}{ }^{2}+\tau_{r}{ }^{2}\right)}{1-\alpha^{2}}\right]
\end{gathered}
$$

Proposition 6. In the first period, the manufacturer decides the equilibrium wholesale price as $w_{1}^{D M R *}=\frac{a\left[\beta \Theta_{1}+\rho \Theta_{2}(\beta-\gamma)\right]+2 C_{L} c_{m} \Theta_{3}(2+\alpha)^{2}\left(\beta^{2}-\gamma^{2}\right)}{\Theta_{4} \Theta_{5}\left(\beta^{2}-\gamma^{2}\right)}$ and the equilibrium selling price as $p_{1 d}^{D M R *}=\frac{a\left[\beta \Theta_{6}-\rho \Theta_{7}(\beta-\gamma)\right]+2 \beta C_{L} c_{m} \Theta_{8}(2+\alpha)^{2}\left(\beta^{2}-\gamma^{2}\right)}{\Theta_{4}\left(\beta^{2}-\gamma^{2}\right)}$; the retailer decides the equilibrium selling price as $p_{1 r}^{D M R *}=\frac{a\left[\Theta_{9}+\rho \Theta_{10}(\beta-\gamma)\right]+2 \beta C_{L} c_{m} \Theta_{11}(2+\alpha)^{2}\left(\beta^{2}-\gamma^{2}\right)}{\Theta_{4} \Theta_{5} \Theta_{12}\left(\beta^{2}-\gamma^{2}\right)}$. In the second period, the manufacturer decides the equilibrium wholesale price as $w_{2}^{D M R *}=\frac{a[\gamma+\rho(\beta-\gamma)]+c_{m}\left(\beta^{2}-\gamma^{2}\right)}{2\left(\beta^{2}-\gamma^{2}\right)}$, the equilibrium selling price as $p_{2 d}^{D M R *}=\frac{a[\beta-\rho(\beta-\gamma)]+c_{m}\left(\beta^{2}-\gamma^{2}\right)}{2\left(\beta^{2}-\gamma^{2}\right)}$, the equilibrium collecting rate as $\tau_{m}^{D M R *}=\frac{\beta\left(1-\alpha^{2}\right)(2+\alpha)^{2}\left(\Delta-b_{c}\right)\left[a\left[\Theta_{13}-2 \rho(\beta-\gamma) \Theta_{14}\right]-4 C_{L} c_{m} \Theta_{15}(3 \beta+\gamma)(2+\alpha)^{2}(\beta-\gamma)\right]}{\Theta_{4} \Theta_{5} \Theta_{12}}$, and the equilibrium transfer price as $b_{r}^{D M R *}=\frac{\Delta+(1+\alpha) b_{c}}{(2+\alpha)}$; the retailer decides the equilibrium selling price as $p_{2 r}^{D M R *}=\frac{a[2 \beta \gamma+\rho(\beta-\gamma)(3 \beta+\gamma)]+c_{m}(\beta+\gamma)\left(\beta^{2}-\gamma^{2}\right)}{4 \beta\left(\beta^{2}-\gamma^{2}\right)}$ and the equilibrium collecting rate as

$$
\tau_{r}^{D M R *}=\frac{\beta\left(1-\alpha^{2}\right)(2+\alpha)\left(\Delta-b_{c}\right)\left[a\left[\Theta_{13}-2 \rho(\beta-\gamma) \Theta_{14}\right]-4 C_{L} c_{m} \Theta_{15}(2+\alpha)^{2}(3 \beta+\gamma)(\beta-\gamma)\right]}{\Theta_{4} \Theta_{5} \Theta_{12}} .
$$

where $\Theta_{1}, \Theta_{2}, \Theta_{3}, \Theta_{4}, \Theta_{5}, \Theta_{6}, \Theta_{7}, \Theta_{8}, \Theta_{9}, \Theta_{10}, \Theta_{11}, \Theta_{12}, \Theta_{13}, \Theta_{14}, \Theta_{15}$ are constants defined in Appendix A.

Remark 1. $w_{2}^{D M *}=w_{2}^{D R *}=w_{2}^{D M R *} ; w_{2}^{S M *}=w_{2}^{S R *}=w_{2}^{S M R *} ; p_{2}^{S M *}=p_{2}^{S R *}=p_{2}^{S M R *}$; $p_{2 r}^{D M *}=p_{2 r}^{D R *}=p_{2 r}^{D M R *} ; p_{2 d}^{D M *}=p_{2 d}^{D R *}=p_{2 d}^{D M R *}$.

This means that in the second period, the wholesale price, the manufacturer's selling price and the retailer's selling price are independent of reverse channel design.

Remark 2. $b_{r}^{D R *}=b_{r}^{S R *}>b_{r}^{D M R *}=b_{r}^{S M R *}$.

This shows that the transfer price when the retailer collects used products is larger than that when the manufacturer and the retailer collect used products simultaneously, which indicates that collection competition can reduce transfer price that is independent of selling channel design.

Remark 3. $\tau_{m}^{D M R *}=(2+\alpha) \tau_{r}^{D M R *} ; \tau_{m}^{S M R *}=(2+\alpha) \tau_{r}^{S M R *}$.

This shows that the manufacturer's collecting rate is larger than the retailer's ones in dual-collecting channel, which indicates that the leading manufacturer would collect more used products than the following retailer so as to gain more profits.

\section{Remark 4.}

$$
\begin{aligned}
& \text { (1) }\left\{\begin{array}{l}
p_{1 d}^{D M *}>p_{1 r}^{D M *}, 0<\rho<\frac{a\left(\beta \Psi_{3} \Psi_{5}-\Psi_{7}\right)-4 C_{L} c_{m} \Psi_{3}(3 \beta+\gamma)\left(\beta^{2}-\gamma^{2}\right)}{2 a(\beta-\gamma)\left(\Psi_{3} \Psi_{6}+\Psi_{8}\right)} \\
p_{1 d}^{D M *} \leq p_{1 r}^{D M *}, \frac{a\left(\beta \Psi_{3} \Psi_{5}-\Psi_{7}\right)-4 C_{L} c_{m} \Psi_{3}(3 \beta+\gamma)\left(\beta^{2}-\gamma^{2}\right)}{2 a(\beta-\gamma)\left(\Psi_{3} \Psi_{6}+\Psi_{8}\right)} \leq \rho<1
\end{array} ;\right. \\
& \text { (2) }\left\{\begin{array}{l}
p_{1 d}^{D R *}>p_{1 r}^{D R *}, 0<\rho<\frac{a\left(\beta \Psi_{3} \Omega_{5} \Omega_{14}-\Omega_{8}\right)-8 \beta C_{L} c_{m}\left(\beta^{2}-\gamma^{2}\right)\left(\Omega_{10}+\Psi_{3} \Omega_{7} \Omega_{14}\right)}{a(\beta-\gamma)\left(\Omega_{9}+\Psi_{3} \Omega_{6} \Omega_{14}\right)} \\
p_{1 d}^{D R *} \leq p_{1 r}^{D R *}, \frac{a\left(\beta \Psi_{3} \Omega_{5} \Omega_{14}-\Omega_{8}\right)-8 \beta C_{L} c_{m}\left(\beta^{2}-\gamma^{2}\right)\left(\Omega_{10}+\Psi_{3} \Omega_{7} \Omega_{14}\right)}{a(\beta-\gamma)\left(\Omega_{9}+\Psi_{3} \Omega_{6} \Omega_{14}\right)} \leq \rho<1
\end{array} ;\right.
\end{aligned}
$$


(3)

$$
\begin{aligned}
& \left\{\begin{array}{l}
p_{1 d}^{D M R *}>p_{1 r}^{D M R *}, 0<\rho<\frac{a\left(\beta \Theta_{5} \Theta_{6} \Theta_{12}-\Theta_{9}\right)-2 \beta C_{L} c_{m}(2+\alpha)^{2}\left(\beta^{2}-\gamma^{2}\right)\left(\Theta_{11}-\Theta_{5} \Theta_{8} \Theta_{12}\right)}{a(\beta-\gamma)\left(\Theta_{5} \Theta_{7} \Theta_{12}+\Theta_{10}\right)} \\
p_{1 d}^{D M R *} \leq p_{1 r}^{D M R *}, \frac{a\left(\beta \Theta_{5} \Theta_{6} \Theta_{12}-\Theta_{9}\right)-2 \beta C_{L} c_{m}(2+\alpha)^{2}\left(\beta^{2}-\gamma^{2}\right)\left(\Theta_{11}-\Theta_{5} \Theta_{8} \Theta_{12}\right)}{a(\beta-\gamma)\left(\Theta_{5} \Theta_{7} \Theta_{12}+\Theta_{10}\right)} \leq \rho<1
\end{array} ;\right. \\
& \left\{\begin{array}{l}
p_{2 d}^{D M *}>p_{2 r}^{D M *}, p_{2 d}^{D R *}>p_{2 r}^{D R *}, p_{2 d}^{D M R *}>p_{2 r}^{D M R *}, 0<\rho<\frac{2 \beta a+c_{m}\left(\beta^{2}-\gamma^{2}\right)}{a(5 \beta+\gamma)} \\
p_{2 d}^{D M *} \leq p_{2 r}^{D M *}, p_{2 d}^{D R *} \leq p_{2 r}^{D R *}, p_{2 d}^{D M R *} \leq p_{2 r}^{D M R *}, \frac{2 \beta a+c_{m}\left(\beta^{2}-\gamma^{2}\right)}{a(5 \beta+\gamma)} \leq \rho<1
\end{array}\right.
\end{aligned}
$$

Remark 4 shows that the share of basic demand for retail channel influences the selling price, whether in the first period or in the second period. When $\rho$ is small enough, the manufacturer's selling price will be larger than the retailer's one for all dual-channel models; however, when $\rho$ is large enough, the retailer's selling price will be larger than the manufacturer's one for all dual-channel models. This indicates that, if the retail channel's share is relatively low compared with e-commerce channel's share, the retailer would reduce its selling price to enhance its competitiveness and enlarge its market share, while the manufacturer would improve its selling price to retain more profits.

\section{Managerial Analysis}

In the previous section, the authors characterized the game between players and deprived the equilibrium solutions in six scenarios, respectively. As the equilibrium solutions cannot be directly compared, the authors will present numerically. Extending the previous research [25], the authors further introduce e-commerce and consider the selling channel and reverse channel strategy simultaneously. Thus, in this subsection, the authors use numerical experiments to obtain critical managerial insights. Parameters are setting as follows: $\alpha=0.2, C_{L}=300, \delta=0.8, b_{c}=2, \Delta=5, a=300, c_{m}=8, \beta=0.8, \gamma=0.5$, and $\rho=0.6$. In all figures, the superscript " $\mathrm{S}$ " and " $\mathrm{D}$ " respectively represent the singlechannel and the dual-channel. $D_{1}^{S *}$ and $D_{2}^{S *}$ respectively represent the market demand for single-channel in the first period and the second period. $D_{1}^{D *}$ (i.e., $=D_{1 r}^{D *}+D_{1 d}^{D *}$ ) and $D_{2}^{D *}$ (i.e., $=D_{2 r}^{D *}+D_{2 d}^{D *}$ ) respectively represent the total market demand for dual-channel in the first period and the second period. $\Pi$ represents the total profit for supply chain.

(a) The comparison of equilibrium solutions

We calculate the equilibrium solutions in Proposition 1-6 based on the above parameter settings. They are presented in Table 3.

\begin{tabular}{|c|c|c|c|c|c|c|c|c|c|c|c|c|}
\hline Model & $w_{1}$ & $p_{1 r}$ & $p_{1 d}$ & $w_{2}$ & $p_{2 r}$ & $p_{2 d}$ & $b_{r}$ & $\tau_{m}$ & $\tau_{r}$ & $\Pi_{m}$ & $\Pi_{r}$ & $\Pi$ \\
\hline SM & 1.059 & 2 & 029 & 191.500 & \multicolumn{2}{|c|}{283.250} & $\mathrm{~N} / \mathrm{A}$ & 0 & $\mathrm{~N} / \mathrm{A}$ & 24 & 12,15 & 36 \\
\hline SR & 191.279 & 2 & 029 & 191.500 & \multicolumn{2}{|c|}{283.250} & 3.500 & $\mathrm{~N}$ & 0184 & 23 & 12,146 & 755 \\
\hline SMR & 190.883 & 282 & 939 & 191.500 & \multicolumn{2}{|c|}{283.250} & 3.364 & 0.354 & 0.161 & $24,289.723$ & $12,167.584$ & $36,457.307$ \\
\hline $\mathrm{DM}$ & 264.750 & 320.398 & 241.673 & 265.539 & 321.039 & 242.462 & $\mathrm{~N} / \mathrm{A}$ & 0.657 & $\mathrm{~N} / \mathrm{A}$ & $57,212.461$ & $44,487.022$ & $101,699.483$ \\
\hline DR & 265.194 & 320.662 & 242.043 & 265.539 & 321.039 & 242.462 & 3.500 & $\mathrm{~N} / \mathrm{A}$ & 0.328 & $57,167.328$ & $44,650.659$ & $101,817.987$ \\
\hline DMR & 264.438 & 320.143 & 241.359 & 265.539 & 321.039 & 242.462 & 3.364 & 0.630 & 0.286 & $57,253.616$ & $44,546.401$ & $101,800.017$ \\
\hline
\end{tabular}

Table 3. The equilibrium solutions.

Claim 1. It can be known from Table 3:

(i)

$$
\begin{array}{ll}
\text { (i) } \quad w_{2}^{D R *}=w_{2}^{D M *}=w_{2}^{D M R *}>w_{1}^{D R *}>w_{1}^{D M *}>w_{1}^{D M R *}>w_{2}^{S R *}=w_{2}^{S M *}=w_{2}^{S M R *}> \\
& w_{1}^{S R *}>w_{1}^{S M *}>w_{1}^{S M R *} ; \\
\text { (ii) } \quad p_{2 r}^{D R *}=p_{2 r}^{D M *}=p_{2 r}^{D M R *}>p_{1 r}^{D R *}>p_{1 r}^{D M *}>p_{1 r}^{D M R}>p_{2}^{S R *}=p_{2}^{S M *}=p_{2}^{S M R *}>p_{1}^{S R *} \\
\quad=p_{1}^{S M *}>p_{1}^{S M R *}>p_{2 d}^{D R *}>p_{2 d}^{D M *}>p_{2 d}^{D M R}>p_{1 d}^{D R *}>p_{1 d}^{D M *}>p_{1 d}^{D M R *} ; \\
\text { (iii) } \tau^{D M R *}>\tau^{S M R *}>\tau_{m}^{D M *}>\tau_{m}^{D M R *}>\tau_{m}^{S M *}>\tau_{m}^{S M R *}>\tau_{r}^{D R *}>\tau_{r}^{D M R *}>\tau_{r}^{S R *}> \\
\\
\quad \tau_{r}^{S M R *} ; \\
\quad \Pi^{D R *}>\Pi^{D M R *}>\Pi^{D M *}>\Pi^{S M R *}>\Pi^{S M *}>\Pi^{S R *}>\Pi_{m}^{D M R *}>\Pi_{m}^{D M *}>\Pi_{m}^{D R *} \\
\quad>\Pi_{r}^{D R *}>\Pi_{r}^{D M R *}>\Pi_{r}^{D M *}>\Pi_{m}^{S M R *}>\Pi_{m}^{S M *}=\Pi_{m}^{S R *}>\Pi_{r}^{S M R *}>\Pi_{r}^{S M *}>\Pi_{r}^{S R *} .
\end{array}
$$


Claim 1 indicates that (1) for single-channel CLSC, the wholesale price is the lowest in SMR model, which impels the retailer to cooperate with the manufacturer; the total collecting rate is also the largest in SMR model that would offset lost profits, since the retailer's selling price is lowest in this case; therefore, the manufacturer, retailer, and system's profits in SMR model are the largest due to "small profits and quick returns". This means that dual-collecting pattern is more beneficial for all members. (2) For dualchannel CLSC, the wholesale price and selling price in DMR model are the lowest, but the total collecting rate in DMR model is the largest; therefore, the manufacturer's profit in DMR model is the largest due to "small profits and quick returns"; however, the retailer cannot obtain profit from the lowest wholesale price due to the e-commerce channel entry, and the retailer's selling price and collecting rate in DR model are the largest, so the retailer's profit is the largest in DR model; the wholesale price, selling price, and total market demand are the largest in DR model; therefore, the system's profit in DR model is the largest. This means that dual-collecting pattern is more profitable to the manufacturer, while retailer collecting pattern is more profitable to the retailer and system. (3) The selling price, wholesale price, and collecting rate in dual-channel are larger than those in singlechannel, so the manufacturer, retailer, and system's profits in dual-channel are all larger than those in single-channel.

(b) Impact of share of basic demand for retail channel $\rho$

Setting $\rho \in[0,1]$, the authors analyze how $\rho$ affect the wholesale price $w$, selling price $p$, market demand $D$, collecting rate $\tau$, and profit $\Pi$.

\section{Claim 2. Figure 4 shows that}

i. $\quad$ The wholesale price increases as $\rho$ increases.

ii. The retailer's selling price increases, but the manufacturer's selling price decreases as $\rho$ increases. The manufacturer's selling price is larger than the retailer's when $0<\rho<0.3578$; however, when $0.3578<\rho<1$, it is the other way around.

iii. Retail channel's market demand increases, while e-commerce channel's and total market demands decrease as $\rho$ increases. E-commerce channel's market demand is larger than retail channel's when $0<\rho<0.8370$; however, when $0.8370<\rho<1$, it is the other way around. iv. $\quad$ The collecting rate decreases as $\rho$ increases, and $\tau^{D M R}>\tau_{m}^{D M}>\tau_{m}^{D M R}>\tau_{r}^{D R}>\tau_{r}^{D M R}$.

v. As $\rho$ increases, the manufacturer's profit decreases, the retailer's profit increases, and the system's profit decreases, but it begins to increase when $\rho$ reaches certain threshold.

Claim 2 indicates that, as the e-commerce preference decreases, retail channel's market demand increases, and e-commerce channel's market demand decreases, leading to the decrease of the total market demand and collecting rate. Therefore, the manufacturer will reduce its selling price to promote products and increase its wholesale price to offset lost profits, yet the retailer will further increase its selling price to get more profits. Moreover, when the e-commerce preference is high, the market demand and selling price of e-commerce channel are larger than those of retail channel, and then the decreasing degree of the manufacturer's profit is larger than the increasing degree of the retailer's profit; consequently, the system's profit will decrease. 

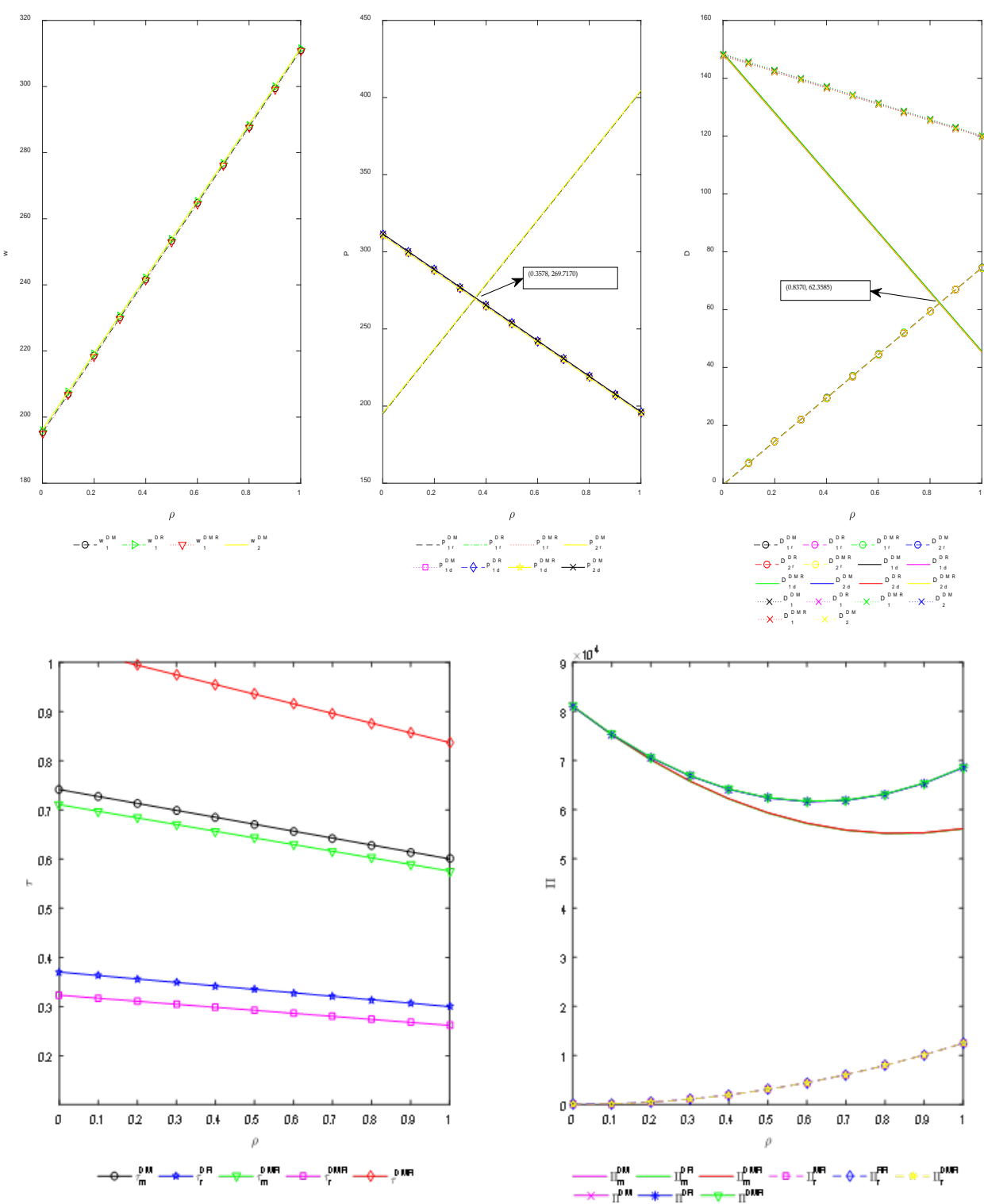

Figure 4. Changes of the wholesale price/selling price/market demand/collecting rate/profit with $\rho$.

(c) Impact of sensitivity coefficient for self-price $\beta$

Setting $\beta \in[0.6,2]$, the authors analyze how $\beta$ affects the wholesale price $w$, selling price $p$, market demand $D$, collecting rate $\tau$, and profit $\Pi$.

Claim 3. Figure 5 shows that

i. $\quad$ As $\beta$ increases, the wholesale price decreases, but the decreasing speed in dual-channel is faster than that in single-channel. In addition, the wholesale price in dual-channel is larger than that in single-channel, but it will be lower than that in single-channel when $\beta$ reaches a certain threshold.

ii. The retailer's selling price decreases as $\beta$ increases, but the decreasing speed in dual-channel is faster than that in single-channel. Furthermore, the retailer's selling price in dual-channel is larger than that in single-channel, but it will be lower than that in single-channel when $\beta$ reaches a certain threshold.

iii. The market demand decreases as $\beta$ increases. Moreover, the manufacturer's market demand is larger than the retailer's market demand in dual-channel; the retailer's market demand 
in single-channel is higher than those in dual-channel; and the total market demand in dual-channel is larger than those in single-channel.

iv. The collecting rate decreases as $\beta$ increases, and $\tau^{D M R}>\tau_{m}^{D M}>\tau_{m}^{D M R}>\tau^{S M R}>\tau_{m}^{S M}>$ $\tau_{m}^{S M R}>\tau_{r}^{D R}>\tau_{r}^{D M R}>\tau_{r}^{S R}>\tau_{r}^{S M R}$.

v. The profit decreases as $\beta$ increases, and the decreasing speed of the manufacturer and the system's profits in dual-channel are the largest. The manufacturer and the system's profits in dual-channel are larger than those in single-channel, but they will be lower than those in single-channel when $\beta$ reaches a certain threshold. The retailer's profit in dual-channel is larger than that in single-channel.
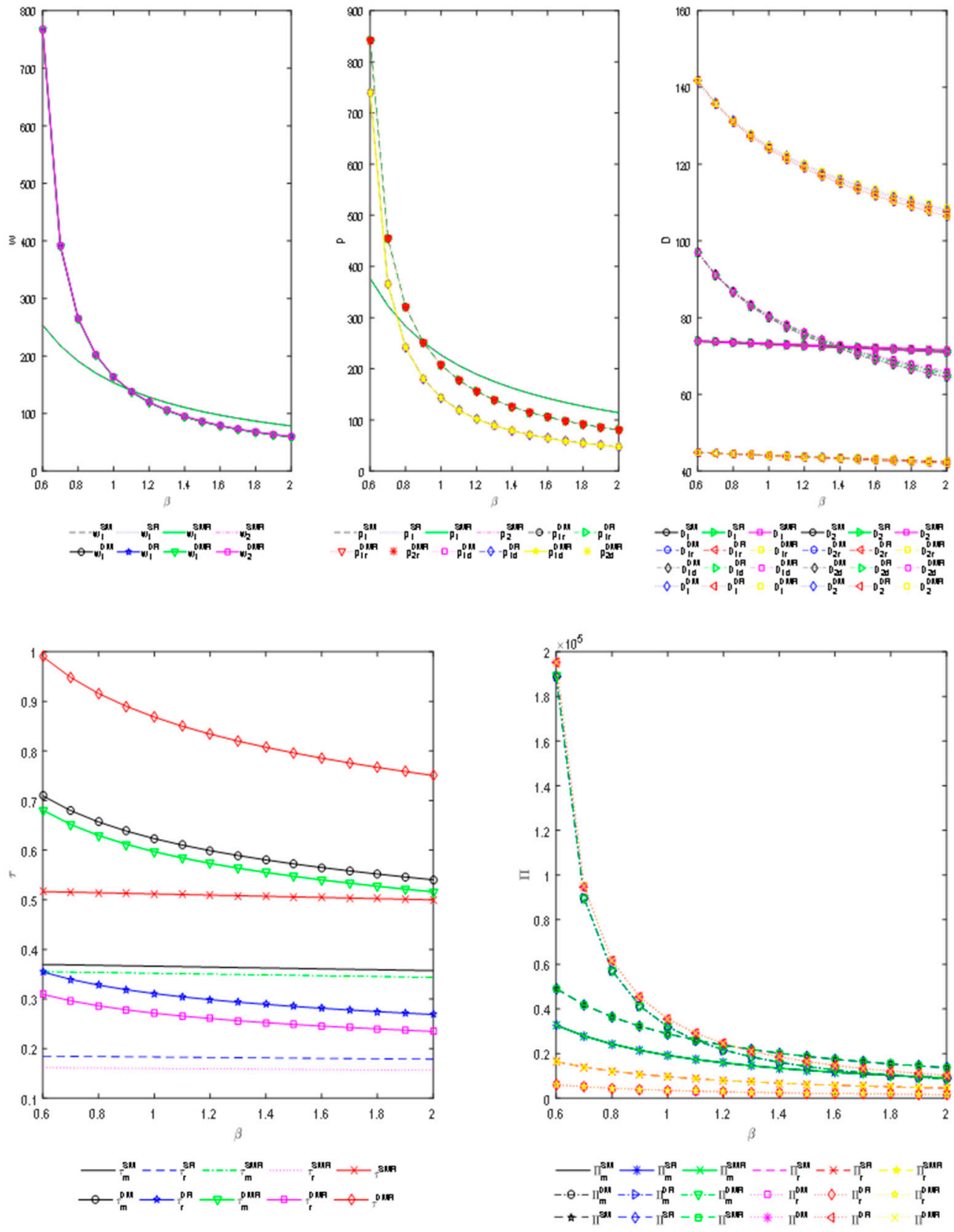

Figure 5. Changes of the wholesale price/selling price/market demand/collecting rate/profit with $\beta$.

Claim 3 indicates that (1) if a firm's self-price sensitivity coefficient increases, then a lower increasing price of self-channel will lead to a higher decreasing self-market demand, thereby decreasing the collecting rate. To promote products, firms will decrease the 
wholesale price and the selling price; however, the lost profits still cannot be offset. (2) The wholesale price and total collecting rate in dual-channel are larger than those in single channel, so the manufacturer's profit in dual-channel is larger than those in single-channel; however, when $\beta$ reaches a certain threshold, the total collecting rate in dual-channel is larger than that in single-channel, but the wholesale price in single-channel is larger than that in dual-channel; consequently, the manufacturer's profit in single-channel is larger than those in dual-channel. The retailer's selling price in dual-channel is larger than that in single-channel, and it will be lower than that in single-channel when $\beta$ reaches a certain threshold, but the market demand in dual-channel is larger than those in single-channel; accordingly, the retailer's profit in dual-channel is larger than those in single-channel. (3) The decreasing speed of the manufacturer and system's profits in dual-channel is the largest, which indicates that dual-channel is more sensitive to self-price sensitivity coefficient than single-channel.

(d) Impact of sensitivity coefficient for cross-price $\gamma$

Setting $\gamma \in[0.4,0.8]$, the authors analyze how $\gamma$ affect the wholesale price $w$, selling price $p$, market demand $D$, collecting rate $\tau$, and profit $\Pi$.

Claim 4. Figure 6 shows that

i. As $\gamma$ increases, the wholesale price increases.

ii. The manufacturer and the retailer's selling price increase as $\gamma$ increases. The retailer's selling price is larger than the manufacturer's.

iii. The market demand increases as $\gamma$ increases. The manufacturer's market demand is larger than the retailer's.

iv. The collecting rate increases as $\gamma$ increases, and $\tau^{D M R}>\tau_{m}^{D M}>\tau_{m}^{D M R}>\tau_{r}^{D R}>\tau_{r}^{D M R}$.

v. The manufacturer and the retailer's profits increase as $\gamma$ increases. The manufacturer's profit and the increasing speed are larger than the retailer's.

Claim 4 indicates that (1) if a firm's cross-price sensitivity coefficient increases, a lower increasing cross-channel price will lead to a higher increasing self-market demand, thereby increasing the collecting rate. To obtain more profits from the increasing market demand, all firms will increase their wholesale price and selling price, which results in the increase of firms' profits. (2) Because e-commerce channel's market demand is larger than those of retail channel's, the retailer's selling price will be larger than the manufacturer's to guarantee enough profits, so the manufacturer's profit is still larger than the retailer's. (3) The increasing speed of the manufacturer's profit is the largest, which means that the manufacturer is more sensitive to cross-price sensitivity coefficient. 

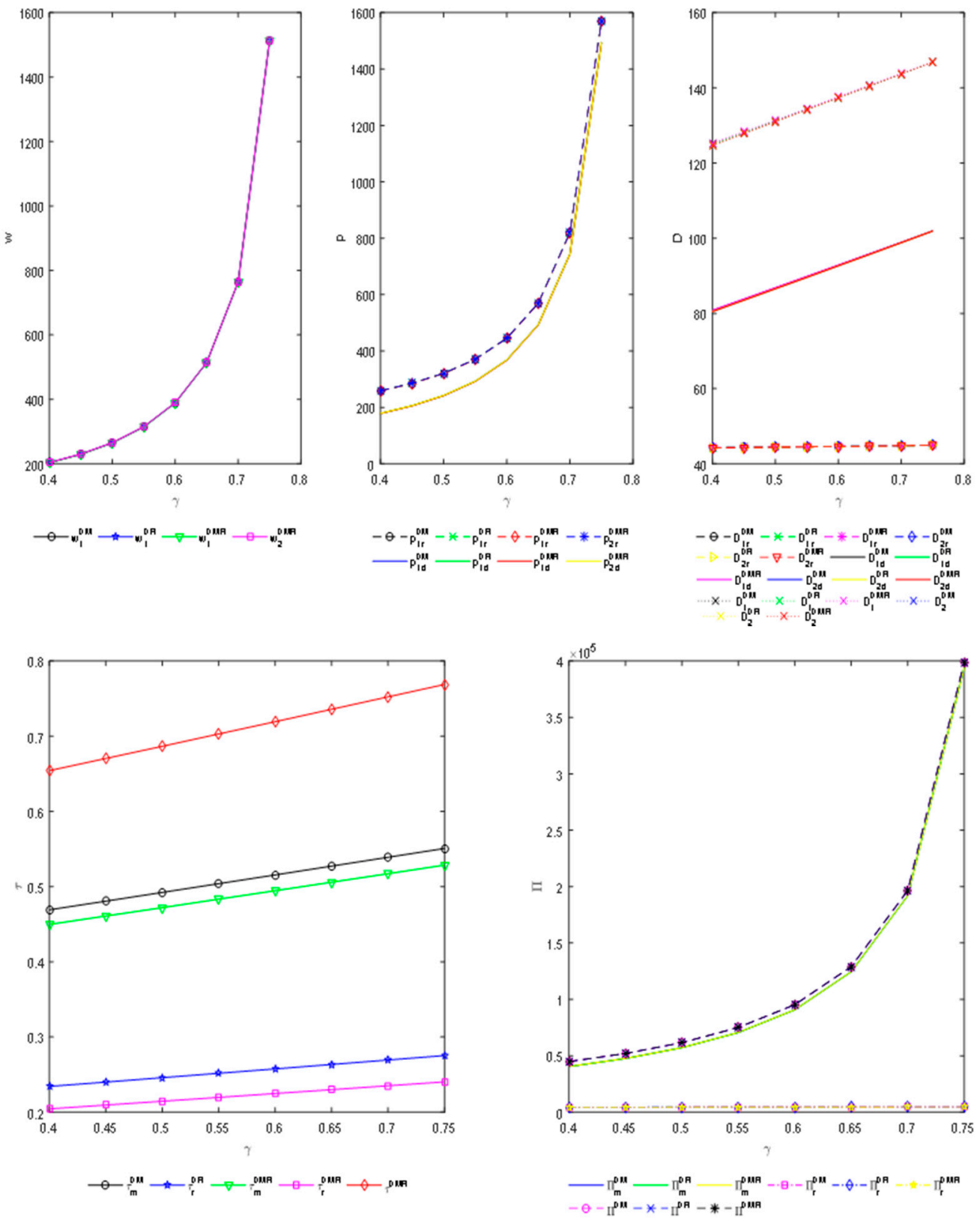

Figure 6. Changes of the wholesale price/selling price/market demand/collecting rate/profit with $\gamma$.

(e) Impact of scale parameter $C_{L}$

Setting $C_{L} \in[300,550]$, the authors analyze how $C_{L}$ affect the wholesale price $w$, selling price $p$, collecting rate $\tau$, market demand $D$, and profit $\Pi$.

Claim 5. Figure 7 shows that

i. In the first period, the wholesale price increases as $C_{L}$ increases, and $w_{1}^{D R}>w_{1}^{D M}>$ $w_{1}^{D M R}>w_{1}^{S R}>w_{1}^{S M}>w_{1}^{S M R}$. In the second period, the wholesale price is independent of $C_{L}$.

ii. In the first period, the manufacturer and the retailer's selling prices increase as $C_{L}$ increases, and $p_{1 r}^{D R}>p_{1 r}^{D M}>p_{1 r}^{D M R}>p_{1}^{S R}=p_{1}^{S M}>p_{1}^{S M R}>p_{1 d}^{D R}>p_{1 d}^{D M}>p_{1 d}^{D M R}$. In the second period, the selling price is independent of $C_{L}$.

iii. The collecting rate decreases as $C_{L}$ increases, and $\tau^{D M R}>\tau_{m}^{D M}>\tau_{m}^{D M R}>\tau^{S M R}>$ $\tau_{m}^{S M}>\tau_{m}^{S M R}>\tau_{r}^{D R}>\tau_{r}^{D M R}>\tau_{r}^{S R}>\tau_{r}^{S M R}$. 
iv. In the first period, the market demand decreases as $C_{L}$ increases, and $D_{1}^{D M R}>D_{1}^{D M}>$ $D_{1}^{D R}>D_{1 d}^{D M R}>D_{1 d}^{D M}>D_{1 d}^{D R}>D_{1}^{S M R}>D_{1}^{S R}=D_{1}^{S M}>D_{1 r}^{D M R}>D_{1 r}^{D M}>D_{1 r}^{D R}$. In the second period, the market demand is independent of $C_{L}$.

v. The profit decreases as $C_{L}$ increases, and $\Pi^{D M R}>\Pi^{D M}>\Pi^{D R}>\Pi_{m}^{D M R}>\Pi_{m}^{D M}>\Pi_{m}^{D R}>\Pi^{S M R}>\Pi^{S M}>\Pi^{S R}>\Pi_{m}^{S M R}$ $>\Pi_{m}^{S M}=\Pi_{m}^{S R}>\Pi_{r}^{S M R}>\Pi_{r}^{S M}>\Pi_{r}^{S R}>\Pi_{r}^{D R}>\Pi_{r}^{D M R}>\Pi_{r}^{D M}$
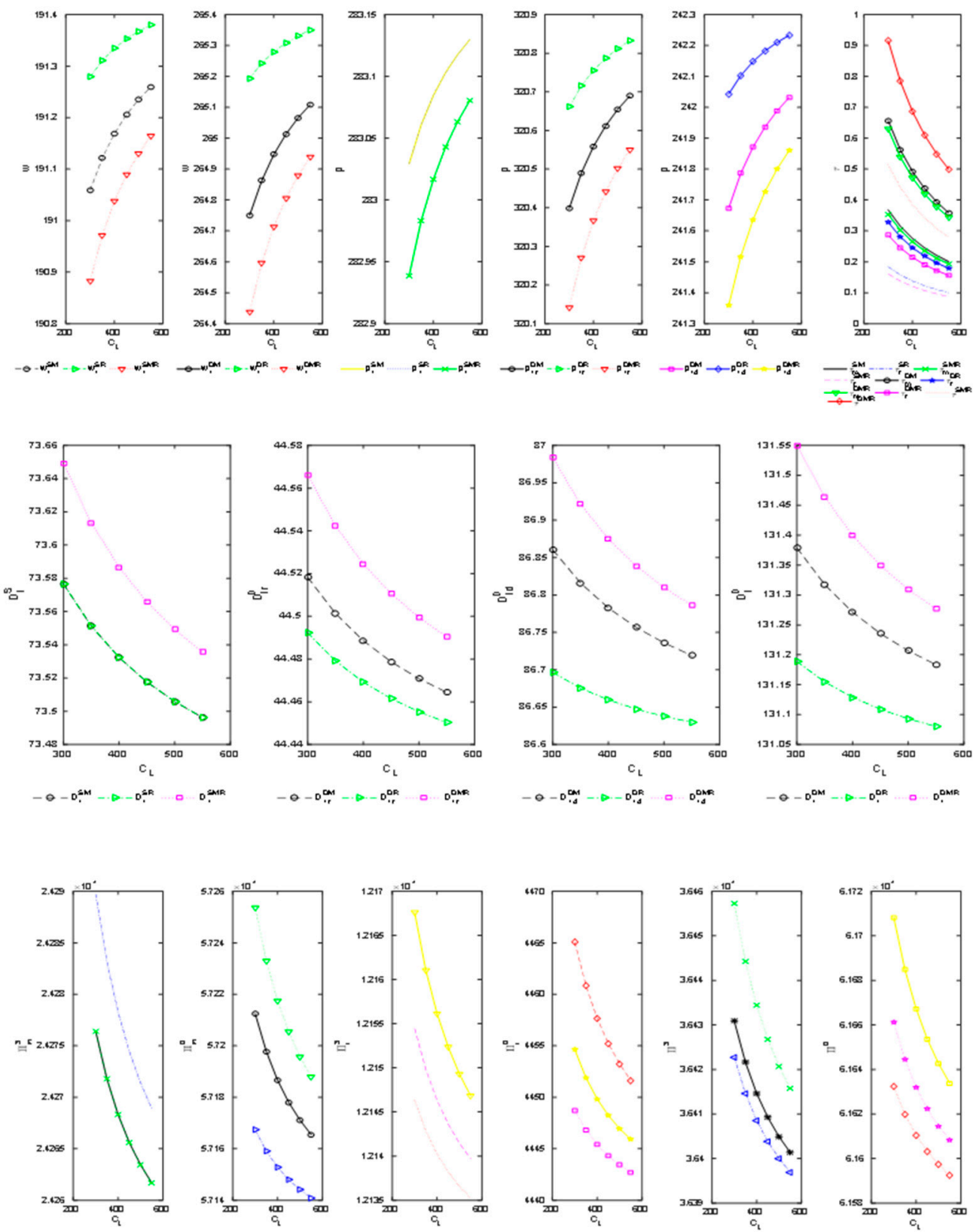

Figure 7. Changes of the wholesale price/selling price/collecting rate/market demand/profit with $C_{L}$.

Claim 5 indicates that (1) if the costs for collecting used products increase, the firm will collect fewer used products. Therefore, the proportion of new products will increase, while the proportion of remanufactured products will decrease, which will lead to the rise of selling price due to higher manufacturing costs. As the market demand decreases due to the increasing selling price, the retailer's profit will decrease. Although the manufacturer 
increases its wholesale price, the lost profits cannot be offset. (2) The wholesale price, selling price, and collecting rate in dual-channel are larger than those in single-channel, but the market demand is shared due to e-commerce channel entry. According to this, the manufacturer and system's profits in dual-channel are larger than those in single-channel, and the retailer's profit in single-channel is larger than those in dual-channel. (3) For singlechannel CLSC, the wholesale price is the lowest in SMR model, which impels the retailer to cooperate with the manufacturer. The total collecting rate and total market demand are also the largest in SMR model; then, the lost profits can be offset, because the retailer's selling price is the lowest in this case. Therefore, the manufacturer, retailer, and system's profits in SMR model are the largest due to "small profits and quick returns". (4) For dual-channel CLSC, the wholesale price and selling price in DMR model are the lowest, and the total collecting rate in DMR model is the largest, so the manufacturer's profit in DMR model is the largest due to "small profits and quick returns". However, the retailer is unable to gain profits from the lowest wholesale price due to the e-commerce channel entry, and the retailer's selling price and collecting rate in DR model are the largest. Accordingly, the retailer's profit is the largest in DR model. The manufacturer, as Stackelberg leader, will make an optimal strategy for both itself and system, so its total profit is the largest in DMR model.

\section{(f) Impact of the remanufacturing level $\Delta$}

Setting $\Delta \in[3,7]$, the authors analyze how $\Delta$ affect the wholesale price $w$, selling price $p$, collecting rate $\tau$, market demand $D$, and profit $\Pi$.

\section{Claim 6. Figure 8 shows that}

i. In the first period, the wholesale price decreases as $\Delta$ increases, and $w_{1}^{D R}>w_{1}^{D M}>w_{1}^{D M R}>$ $w_{1}^{S R}>w_{1}^{S M}>w_{1}^{S M R}$. In the second period, the wholesale price is independent of $\Delta$.

ii. In the first period, the manufacturer and the retailer's selling price decrease as $\Delta$ increases, and $p_{1 r}^{D R}>p_{1 r}^{D M}>p_{1 r}^{D M R}>p_{1}^{S R}=p_{1}^{S M}>p_{1}^{S M R}>p_{1 d}^{D R}>p_{1 d}^{D M}>p_{1 d}^{D M R}$. In the second period, the selling price is independent of $\Delta$.

iii. The collecting rate increases as $\Delta$ increases, and $\tau^{D M R}>\tau_{m}^{D M}>\tau_{m}^{D M R}>\tau^{S M R}>\tau_{m}^{S M}>$ $\tau_{m}^{S M R}>\tau_{r}^{D R}>\tau_{r}^{D M R}>\tau_{r}^{S R}>\tau_{r}^{S M R}$.

iv. In the first period, the market demand increases as $\Delta$ increases, and $D_{1}^{D M R}>D_{1}^{D M}>$ $D_{1}^{D R}>D_{1 d}^{D M R}>D_{1 d}^{D M}>D_{1 d}^{D R}>D_{1}^{S M R}>D_{1}^{S R}=D_{1}^{S M}>D_{1 r}^{D M R}>D_{1 r}^{D M}>D_{1 r}^{D R}$. In the second period, the market demand is independent of $\Delta$.

v. The profit increases as $\quad$ as increases,
$\begin{aligned} \Pi^{D M R}>\Pi^{D M}>\Pi^{D R}>\Pi_{m}^{D M R}>\Pi_{m}^{D M}>\Pi_{m}^{D R}>\Pi^{S M R}>\Pi^{S M}>\Pi^{S R}>\Pi_{m}^{S M R} \\ >\Pi_{m}^{S M}=\Pi_{m}^{S R}>\Pi_{r}^{S M R}>\Pi_{r}^{S M}>\Pi_{r}^{S R}>\Pi_{r}^{D R}>\Pi_{r}^{D M R}>\Pi_{r}^{D M}\end{aligned}$

Claim 6 indicates that (1) if the remanufacturing level is high, the manufacturer put more effort into collecting used products, and then the wholesale price and selling price will decrease due to the increase of product quantity, which will further result in the increase of the market demand and profit. (2) The wholesale price, selling price, and collecting rate in dual-channel are all larger than those in single-channel, but the market demand is shared due to e-commerce channel entry; accordingly, the manufacturer and system's profits in dual-channel are larger than those in single-channel, and the retailer's profit in single-channel is larger than those in dual-channel. (3) For single-channel CLSC, the wholesale price is the lowest in SMR model, which impels the retailer to cooperate with the manufacturer; the total collecting rate and total market demand are the largest in SMR model, and thus, the lost profits can be offset, because the retailer's selling price is the lowest in this case. Therefore, the manufacturer, retailer, and system's profits in SMR model are the largest. (4) For dual-channel CLSC, the wholesale price and selling price are the lowest in DMR model, and the total collecting rate in DMR model is the largest. Therefore, the manufacturer's profit in DMR model is the largest due to "small profits and quick returns"; however, the retailer cannot obtain profits from the lowest wholesale price due 
to the e-commerce channel entry, and the retailer's selling price and collecting rate in DR model are the largest. As a consequent, the retailer's profit is the largest in DR model.
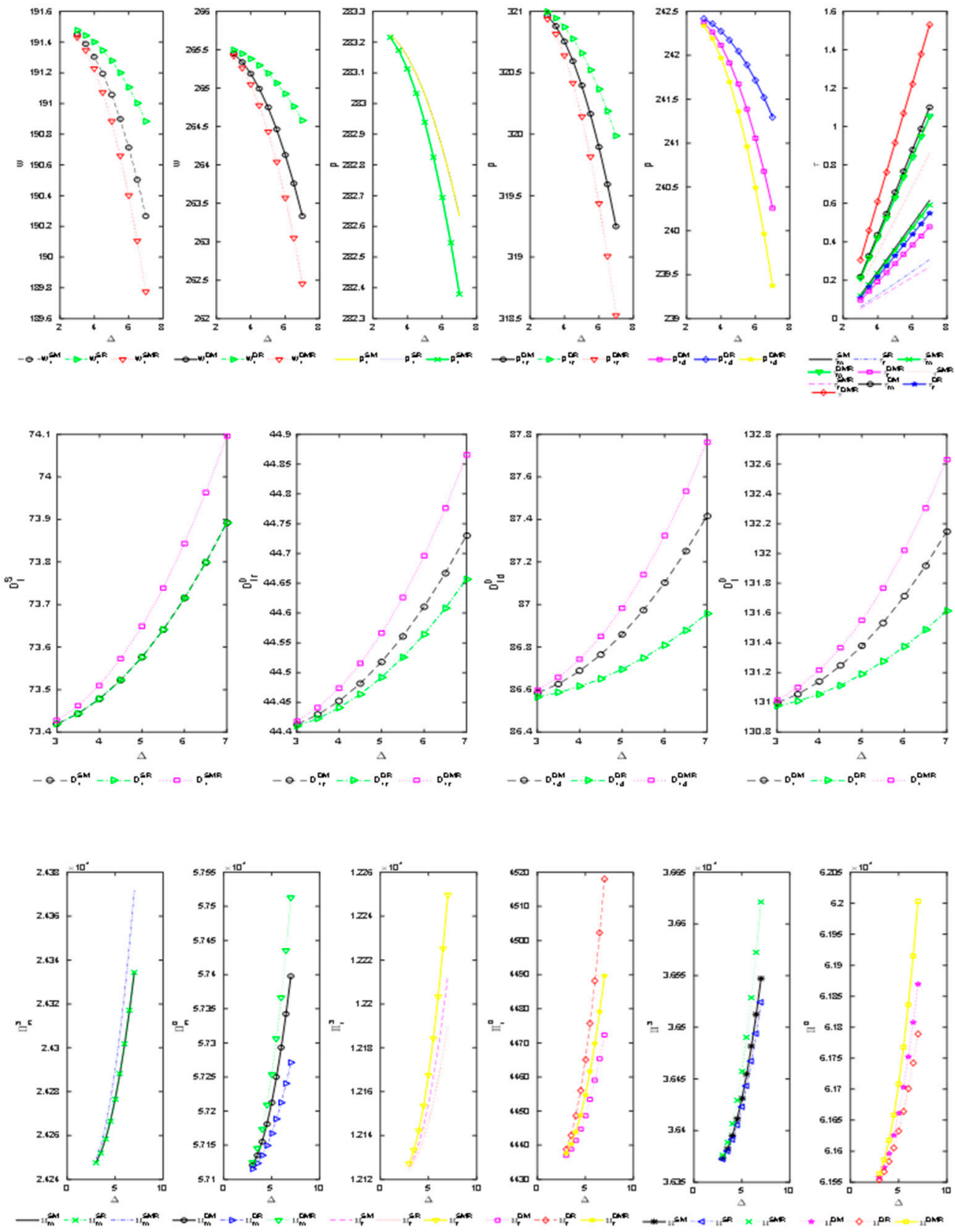

Figure 8. Changes of the wholesale price/selling price/collecting rate/market demand/profit with $\Delta$.

\section{(g) Impact of the discount coefficient $\delta$}

Setting $\delta \in[0.2,0.8]$, the authors analyze how $\delta$ affect the wholesale price $w$, selling price $p$, collecting rate $\tau$, market demand $D$, and profit $\Pi$.

Claim 7. Figure 9 shows that

i. In the first period, the wholesale price decreases as $\delta$ increases, and $w_{1}^{D R}>w_{1}^{D M}>w_{1}^{D M R}>$ $w_{1}^{S R}>w_{1}^{S M}>w_{1}^{S M R}$. In the second period, the wholesale price is independent of $\delta$. 
ii. In the first period, the selling price decreases as $\delta$ increases, and $p_{1 r}^{D R}>p_{1 r}^{D M}>p_{1 r}^{D M R}>$ $p_{1}^{S R}=p_{1}^{S M}>p_{1}^{S M R}>p_{1 d}^{D R}>p_{1 d}^{D M}>p_{1 d}^{D M R}$. In the second period, the selling price is independent of $\delta$.

iii. The collecting rate increases along with $\delta$, and $\tau^{D M R}>\tau_{r}^{D R}>\tau_{r}^{D M R}>\tau_{m}^{D M}>\tau_{m}^{S M}>$ $\tau_{m}^{S M R}>\tau_{m}^{D M R}>\tau^{S M R}>\tau_{r}^{S R}>\tau_{r}^{S M R}$.

iv. In the first period, the market demand increases along with $\delta$, and $D_{1}^{D M R}>D_{1}^{D M}>D_{1}^{D R}>$ $D_{1 d}^{D M R}>D_{1 d}^{D M}>D_{1 d}^{D R}>D_{1}^{S M R}>D_{1}^{S R}=D_{1}^{S M}>D_{1 r}^{D M R}>D_{1 r}^{D M}>D_{1 r}^{D R}$. In the second period, the market demand is independent of $\delta$.

v. The manufacturer and the retailer's profits increase as $\delta$ increases. The manufacturer and system's profits in dual-channel are larger than those in single-channel; the retailer's profit in single-channel is larger than those in dual-channel.

Claim 7 indicates that (1) the increasing discount coefficient indicates that the expected profit in the second period increases. Therefore, firms will decrease the selling price and wholesale price, which results in the increase of the market demand and collecting rate. (2) The equilibrium wholesale price, selling price, and collecting rate in dual-channel are all larger than those in single-channel, but the market demand is shared, so the retailer's market demand in dual-channel is lower than those in single-channel; accordingly, the manufacturer and system's profits in dual-channel are larger than those in single-channel, and the retailer's profit in single-channel is larger than those in dual-channel.
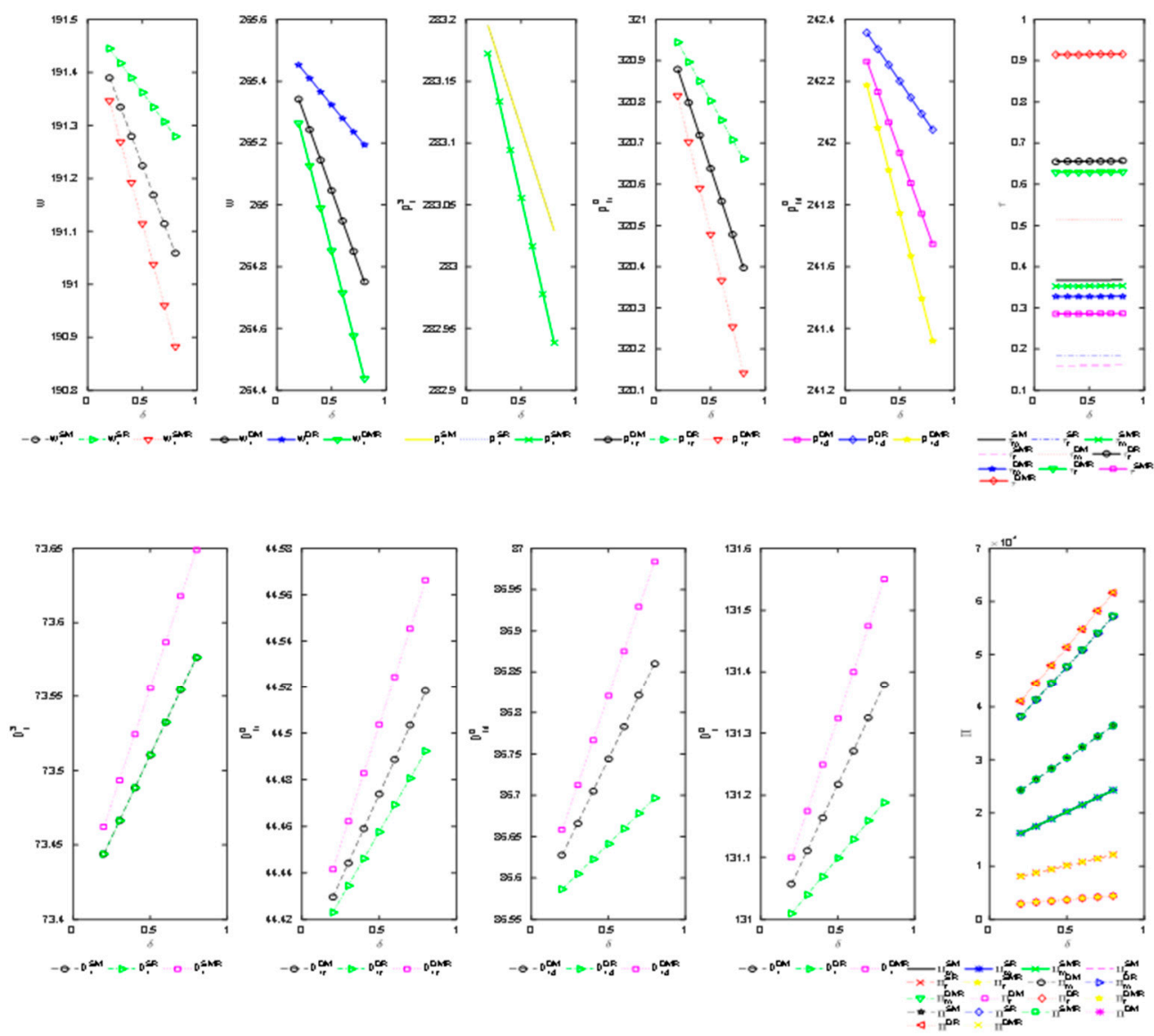

Figure 9. Changes of the wholesale price/selling price/collecting rate/market demand/profit with $\delta$.

\section{(h) Impact of the collecting competition coefficient $\alpha$}

It can be known from the above analysis that the manufacturer prefers dual-collecting channel. Therefore, the authors analyze how $\alpha$ affect the wholesale price $w$, collecting rate $\tau$, selling price $p$, market demand $D$, and profit $\Pi$ by setting $\alpha \in[0.1,0.9]$. 
Claim 8. Figure 10 shows that

i. $\quad$ The wholesale price increases as $\alpha$ increases, and $w_{1}^{D M R}>w_{1}^{S M R}$.

ii. The collecting rate decreases as $\alpha$ increases, and $\tau^{D M R}>\tau_{m}^{D M R}>\tau^{S M R}>\tau_{m}^{S M R}>$ $\tau_{r}^{D M R}>\tau_{r}^{S M R}$.

iii. $\quad$ The selling price increases as $\alpha$ increases, and $p_{1 r}^{D M R}>p_{1}^{S M R}>p_{1 d}^{D M R}$.

iv. $\quad$ The market demand decreases as $\alpha$ increases, and $D_{1}^{D M R}>D_{1 d}^{D M R}>D_{1}^{S M R}>D_{1 r}^{D M R}$.

v. The manufacturer and the retailer's profits decrease as $\alpha$ increases, but the retailer's profit in $D M R$ model begins to increase when $\alpha$ reaches certain threshold, and $\Pi^{D M R}>\Pi_{m}^{D M R}>$ $\Pi^{S M R}>\Pi_{m}^{S M R}>\Pi_{r}^{S M R}>\Pi_{r}^{D M R}$.
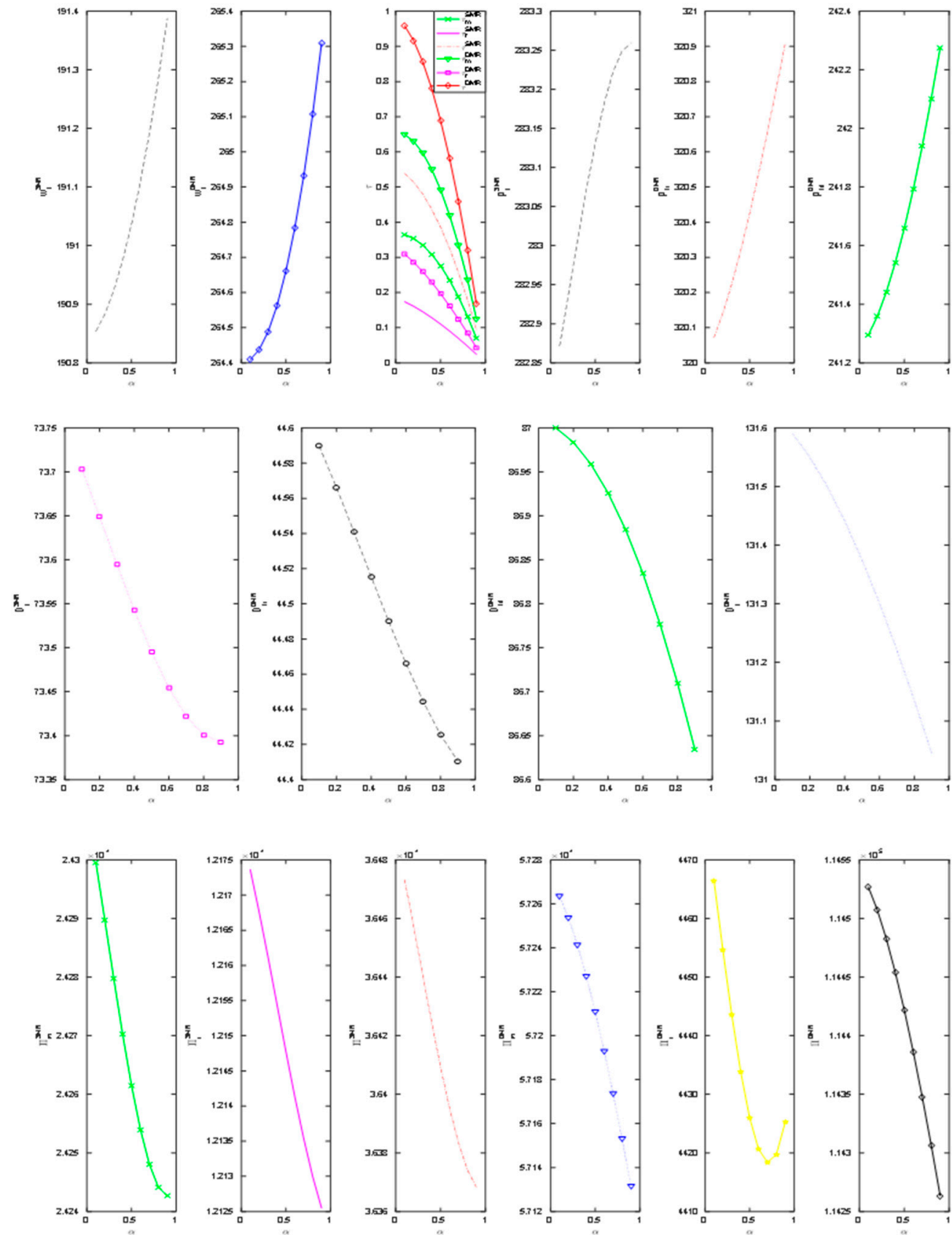

Figure 10. Changes of the wholesale price/collecting rate/selling price/market demand/profit with $\alpha$. 
Claim 8 indicates that (1) if the collecting competition becomes intense, the collecting rate will decline due to the business strategies of members. Therefore, due to the increasing costs for production, firms will increase the wholesale price and selling price to offset lost profits. It indicates that the collection rate will be improved if the manufacturer and retailer have a good cooperation. (2) In SMR model, the wholesale price and selling price increase, but the collecting rate and total market demand decrease, resulting in the decrease of the manufacturer and retailer's profits. In DMR model, the wholesale price and selling price increase, but the collecting rate and total market demand decrease, resulting in the decrease of the manufacturer and retailer's profits; however, the retailer's profit will increase when the competition coefficient reaches a certain threshold due to the high selling price.

From the above analysis, the authors can see that the collecting competition plays an important role. To further explore the impact of collecting competition coefficient on reverse channel strategy, the authors set different value of $\alpha$. The profits for the manufacturer, retailer, and system are shown in Tables 4 and 5, respectively.

Claim 9. It can be known from Table 4

i. When the collecting competition coefficient is relatively small, dual-collecting channel is the best for the manufacturer, retailer, and system.

ii. When the collecting competition coefficient is relatively large, single-collecting channel (manufacturer collecting or retailer collecting) is the best for them.

Generally, dual-collection can achieve win-win for members. However, when the collecting competition becomes intense, collecting used products by the manufacturer or the retailer is indifferent. This is because only the retailer sells products via retail channel.

Claim 10. It can be known from Table 5

i. When the collecting competition coefficient is small enough, dual-collecting channel is the best for the manufacturer, retailer, and system.

ii. When the collecting competition coefficient is relatively small, dual-collecting channel is the best for the manufacturer and system, while retailer collecting channel is the best for the retailer.

iii. When the collecting competition coefficient is relatively large, manufacturer collecting channel is the best for the manufacturer and system, while retailer collecting channel is the best for the retailer.

Without collecting competition, dual-collecting achieves a win-win for members. When the competition increases slowly, the manufacturer still prefers dual-collecting channel, while the retailer prefers retailer collecting channel. This is because the market is shared with e-commerce entry. When the competition becomes intense, the manufacturer and retailer prefer collecting used products by themselves.

Table 4. Single-selling models.

\begin{tabular}{ccccccc}
\hline Profit & Model & $\boldsymbol{\alpha}=\mathbf{0 . 1}$ & $\boldsymbol{\alpha}=\mathbf{0 . 3}$ & $\boldsymbol{\alpha}=\mathbf{0 . 5}$ & $\boldsymbol{\alpha}=\mathbf{0 . 7}$ & $\boldsymbol{\alpha}=\mathbf{0 . 9}$ \\
\hline \multirow{3}{*}{$\Pi_{m}$} & SM & $24,276.423$ & $24,276.423$ & $24,276.423$ & $24,276.423$ & $24,276.423$ \\
& SR & $24,276.423$ & $24,276.423$ & $24,276.423$ & $24,276.423$ & $24,276.423$ \\
& SMR & $24,299.603$ & $24,279.792$ & $24,261.498$ & $24,248.056$ & $24,242.685$ \\
\hline & SM & $12,154.452$ & $12,154.452$ & $12,154.452$ & $12,154.452$ & $12,154.452$ \\
$\Pi_{r}$ & SR & $12,146.332$ & $12,146.332$ & $12,146.332$ & $12,146.332$ & $12,146.332$ \\
& SMR & $12,173.617$ & $12,161.111$ & $12,147.764$ & $12,135.331$ & $12,125.472$ \\
\hline$\Pi$ & SM & $36,430.875$ & $36,430.875$ & $36,430.875$ & $36,430.875$ & $36,430.875$ \\
& SR & $36,422.755$ & $36,422.755$ & $36,422.755$ & $36,422.755$ & $36,422.755$ \\
\hline
\end{tabular}


Table 5. Dual-selling models.

\begin{tabular}{ccccccc}
\hline Profit & Model & $\boldsymbol{\alpha}=\mathbf{0 . 1}$ & $\boldsymbol{\alpha}=\mathbf{0 . 3}$ & $\boldsymbol{\alpha}=\mathbf{0 . 5}$ & $\boldsymbol{\alpha}=\mathbf{0 . 7}$ & $\boldsymbol{\alpha}=\mathbf{0 . 9}$ \\
\hline \multirow{3}{*}{$\Pi_{m}$} & DM & $57,212.461$ & $57,212.461$ & $57,212.461$ & $57,212.461$ & $57,212.461$ \\
& DR & $57,167.328$ & $57,167.328$ & $57,167.328$ & $57,167.328$ & $57,167.328$ \\
& DMR & $57,263.489$ & $57,241.400$ & $57,210.894$ & $57,173.767$ & $57,131.666$ \\
\hline$\Pi_{r}$ & DM & 4448.702 & 4448.702 & 4448.702 & 4448.702 & 4448.702 \\
& DR & 4465.066 & 4465.066 & 4465.066 & 4465.066 & 4465.066 \\
& DMR & 4466.463 & 4443.561 & 4425.989 & 4418.379 & 4425.272 \\
\hline$\Pi$ & DM & $61,661.163$ & $61,661.163$ & $61,661.163$ & $61,661.163$ & $61,661.163$ \\
& DR & $61,632.394$ & $61,632.394$ & $61,632.394$ & $61,632.394$ & $61,632.394$ \\
\hline
\end{tabular}

\section{Discussions and Conclusions}

As Savaskan et al. [3] have illustrated early, outsourcing the collecting activity to the retailer is always the optimal. Giovanni et al. [25] extended [3] to a two-period framework taking into account reverse channel design from the environment and operation performance, which found that the manufacturer would outsource the collecting activity to the retailer or the third-party when they perform better in the environment and operation performance and outsource to the retailer when they have equal performance. Mondal et al. [26] extended [25] to a dual-collecting framework taking into account reverse channel design from green innovation and marketing, which found that the manufacturer would cooperate with the retailer, i.e., dual-collecting is the optimal. Inspired by the above literatures and the current social hotspots, the authors extend [26] to an e-commerce framework. To be specific, this paper studied the selling channel and the reverse channel strategy of a two-period closed-loop supply chain considering e-commerce. Firstly, six direct reverse channel, indirect reverse channel, and dual reverse channel two-period CLSC models considering single- and dual-selling models, respectively, were formulated, and all equilibrium solutions were deprived. Secondly, analysis was conducted through numerical experiments. Finally, some new management insights were observed, and some critical suggestions for firms to add e-commerce channel and collect used products were given.

The main conclusions of this paper are the following: The collecting competition between members plays a critical role in reverse channel strategy. (1) For single-selling channel two-period CLSC, dual-collecting mode is more beneficial to the manufacturer, the retailer, and the system, while single-collecting mode is more beneficial when the collecting competition is relatively large. (2) For dual-selling channel two-period CLSC, dual-collecting mode is more beneficial to the manufacturer and the system, while manufacturer collecting mode is more beneficial when the collecting competition is relatively large. Retailer collecting mode is more beneficial to the retailer, while dual-collecting mode is more beneficial when the collecting competition is small enough. (3) The manufacturer should operate a dual-selling channel, and, accompanied by the increase of customer's e-commerce preference, the market demand, the collecting rate, and the manufacturer's profit in the operating period will increase. (4) Affected by the high remanufacturing level and discount coefficient, the market demand in the first period, the collecting rate in the second period, and all members' and the system's profits in the operating period will be higher.

Inspired by the study, some directions can be further explored, such as (1) this study is studied based on deterministic market demand. However, the supply chain is usually faced with various risks such as natural disasters, infectious diseases, food safety, and policy adjustment, thereby making original decisions infeasible. Thus, dual-channel two-period CLSC under demand or cost uncertainty is suggested. (2) This study assumes that the selling price of new products and remanufactured products is identical. However, the 
fact is that new products and remanufactured products differ in quality, so considering differential pricing is necessary.

Author Contributions: Conceptualization, Data Curation, Software, Investigation, L.Z.; Formal Analysis, L.Z. and Z.M.; Writing-Original Draft, L.Z.; Writing-Review and Editing, Z.M. Both authors have read and agreed to the published version of the manuscript.

Funding: This research was funded by Natural Science Foundation of Shandong Province, grant number ZR2017BG002.

Institutional Review Board Statement: Not applicable.

Informed Consent Statement: Not applicable.

Data Availability Statement: Not applicable.

Acknowledgments: The authors would like to thank the editors of Mathematics and the anonymous reviewers for the interest given to the work and for the valuable comments, which improved the paper. The authors would like also to thank Natural Science Foundation of Shandong Province for supporting this project.

Conflicts of Interest: The authors declare no conflict of interest.

\section{Appendix A}

$$
\begin{gathered}
A_{1}=8 \beta C_{L}-\delta(\beta-\gamma)^{2}\left(\Delta-b_{c}\right)^{2} \\
A_{2}=8 \beta C_{L}\left(2 \beta^{2}-\gamma^{2}\right)-\delta(2 \beta+\gamma)^{2}(\beta-\gamma)^{2}\left(\Delta-b_{c}\right)^{2} \\
A_{3}=8 \beta C_{L} \gamma+\delta(2 \beta+\gamma)(\beta-\gamma)^{2}\left(\Delta-b_{c}\right)^{2}
\end{gathered}
$$

$$
\Psi_{1}=64 \beta^{2} C_{L}^{2} \gamma-16 \beta^{2} C_{L} \delta(\beta+3 \gamma)(\beta-\gamma)\left(\Delta-b_{c}\right)^{2}+\delta^{2}(\beta-\gamma)^{3}\left(\Delta-b_{c}\right)^{4}\left(2 \beta^{2}+5 \beta \gamma+\gamma^{2}\right)
$$

$$
\Psi_{2}=32 \beta C_{L}^{2}-4 C_{L} \delta(3 \beta-\gamma)(\beta-\gamma)\left(\Delta-b_{c}\right)^{2}+\delta^{2}(\beta-\gamma)^{3}\left(\Delta-b_{c}\right)^{4}, \Psi_{3}=8 \beta C_{L}-\delta(\beta-\gamma)^{2}\left(\Delta-b_{c}\right)^{2}
$$

$\Psi_{4}=8 \beta C_{L}-\delta(3 \beta+\gamma)(\beta-\gamma)\left(\Delta-b_{c}\right)^{2}, \Psi_{5}=8 \beta C_{L}-\delta(5 \beta+3 \gamma)(\beta-\gamma)\left(\Delta-b_{c}\right)^{2} . \Psi_{6}=4 \beta C_{L}-\delta(2 \beta+\gamma)(\beta-\gamma)\left(\Delta-b_{c}\right)^{2}$

$$
\begin{gathered}
\Psi_{7}=64 \beta^{2} C_{L}{ }^{2} \gamma-8 \beta C_{L} \delta(\beta-\gamma)\left(\Delta-b_{c}\right)^{2}\left(\beta^{2}+6 \beta \gamma+\gamma^{2}\right)+\delta^{2}(\beta-\gamma)^{3}\left(\Delta-b_{c}\right)^{4}\left(\beta^{2}+5 \beta \gamma+2 \gamma^{2}\right) \\
\Psi_{8}=16 \beta C_{L}{ }^{2}(3 \beta+\gamma)-2 C_{L} \delta(\beta-\gamma)\left(\Delta-b_{c}\right)^{2}\left(11 \beta^{2}+2 \beta \gamma-\gamma^{2}\right)+\delta^{2}(2 \beta+\gamma)(\beta-\gamma)^{3}\left(\Delta-b_{c}\right)^{4} \\
B_{1}=8 \beta C_{L}-\delta(\beta-\gamma)^{2}\left(\Delta-b_{c}\right)^{2} \\
B_{2}=256 \beta^{2} C_{L}{ }^{2} \gamma+16 \beta C_{L} \delta(\beta-\gamma)^{3}\left(\Delta-b_{c}\right)^{2}+\delta^{2}(\beta+\gamma)(\beta-\gamma)^{4}\left(\Delta-b_{c}\right)^{4} \\
B_{3}=128 \beta C_{L}{ }^{2}\left(2 \beta^{2}-\gamma^{2}\right)-16 \beta C_{L} \delta(4 \beta+3 \gamma)(\beta-\gamma)^{2}\left(\Delta-b_{c}\right)^{2}+\delta^{2}(\beta+\gamma)(\beta-\gamma)^{4}\left(\Delta-b_{c}\right)^{4}
\end{gathered}
$$


$\Omega_{1}=256^{2} \beta^{4} C_{L}^{5} \gamma 8-32^{3} \beta^{3} C_{L}^{4} \delta(\beta-\gamma)\left(\Delta-b_{c}\right)^{2}\left(\beta^{2}+10 \beta \gamma-3 \gamma^{2}\right)+256 \beta^{2} C_{L}^{3} \delta^{2}(\beta-\gamma)^{3}\left(\Delta-b_{c}\right)^{4}\left(3 \beta^{2}+28 \beta \gamma-\gamma^{2}\right)^{8}$

$-128 \beta C_{L}^{2} \delta^{3}(\beta-\gamma)^{5}\left(\Delta-b_{c}\right)^{6}\left(\beta^{2}+28 \beta \gamma+3 \gamma^{2}\right)-8 C_{L} \delta^{4}(\beta-\gamma)^{7}\left(\Delta-b_{c}\right)^{8}\left(3 \beta^{2}-7 \beta \gamma-2 \gamma^{2}\right)+\delta^{5}(\beta+\gamma)(\beta-\gamma)^{9}\left(\Delta-b_{c}\right)^{10}$

$\Omega_{2}=256^{2} \beta^{5} C_{L}^{5} 8-128^{2} \beta^{3} C_{L}^{4} \delta(\beta-\gamma)\left(\Delta-b_{c}\right)^{2}\left(16 \beta^{2}-9 \beta \gamma-\gamma^{2}\right)+64^{2} \beta^{2} C_{L}^{3} \delta^{2}(\beta-\gamma)^{3}\left(\Delta-b_{c}\right)^{4}\left(11 \beta^{2}-3 \beta \gamma-\gamma^{2}\right)$

$-64 \beta C_{L}^{2} \delta^{3}(\beta-\gamma)^{5}\left(\Delta-b_{c}\right)^{6}\left(52 \beta^{2}-\beta \gamma-5 \gamma^{2}\right)+8 C_{L} \delta^{4}(\beta-\gamma)^{7}\left(\Delta-b_{c}\right)^{8}\left(13 \beta^{2}+4 \beta \gamma-\gamma^{2}\right)-\delta^{5}(\beta+\gamma)(\beta-\gamma)^{9}\left(\Delta-b_{c}\right)^{10}$

$\Omega_{3}=256^{2} \beta^{5} C_{L}^{4}-256 \beta^{3} C_{L}^{3} \delta(12 \beta+\gamma)(\beta-\gamma)^{2}\left(\Delta-b_{c}\right)^{2} 8+256 \beta^{2} C_{L}^{2} \delta^{2}(13 \beta+2 \gamma)(\beta-\gamma)^{4}\left(\Delta-b_{c}\right)^{4}$ $-8 \beta C_{L} \delta^{3}(24 \beta+5 \gamma)(\beta-\gamma)^{6}\left(\Delta-b_{c}\right)^{6}+\delta^{4}(4 \beta+\gamma)(\beta-\gamma)^{8}\left(\Delta-b_{c}\right)^{8}$

$\Omega_{4}=256^{2} \beta^{4} C_{L}^{4} 2-128^{2} \beta^{3} C_{L}^{3} \delta(3 \beta-\gamma)(\beta-\gamma)\left(\Delta-b_{c}\right)^{2}+256 \beta^{2} C_{L}^{2} \delta^{2}(17 \beta-3 \gamma)(\beta-\gamma)^{3}\left(\Delta-b_{c}\right)^{4}$ $-32 \beta C_{L} \delta^{3}(3 \beta-\gamma)(\beta-\gamma)^{5}\left(\Delta-b_{c}\right)^{6}-\delta^{4}(\beta+\gamma)(\beta-\gamma)^{7}\left(\Delta-b_{c}\right)^{8}$

$\Omega_{5}=256^{2} \beta^{4} C_{L}{ }^{4}-32^{3} \beta^{4} C_{L}^{3} \delta(\beta-\gamma)\left(\Delta-b_{c}\right)^{2}+512 \beta^{2} C_{L}^{2} \delta^{2}(6 \beta+\gamma)(\beta-\gamma)^{3}\left(\Delta-b_{c}\right)^{4}-64 \beta^{2} C_{L} \delta^{3}(\beta-\gamma)^{5}\left(\Delta-b_{c}\right)^{6}$ $-\delta^{4}(\beta+\gamma)(\beta-\gamma)^{7}\left(\Delta-b_{c}\right)^{8}$

$\Omega_{6}=256^{2} \beta^{4} C_{L}{ }^{4}-256 \beta^{3} C_{L}^{3} \delta(13 \beta-3 \gamma)(\beta-\gamma)\left(\Delta-b_{c}\right)^{2} 8+256 \beta^{2} C_{L}^{2} \delta^{2}(9 \beta-\gamma)(\beta-\gamma)^{3}\left(\Delta-b_{c}\right)^{4}$ $-8 \beta C_{L} \delta^{3}(5 \beta-3 \gamma)(\beta-\gamma)^{5}\left(\Delta-b_{c}\right)^{6}-\delta^{4}(\beta+\gamma)(\beta-\gamma)^{7}\left(\Delta-b_{c}\right)^{8}$

$\Omega_{7}=512 \beta^{3} C_{L}^{3} 16-256 \beta^{2} C_{L}^{2} \delta(\beta-\gamma)^{2}\left(\Delta-b_{c}\right)^{2} 5+64 \beta C_{L} \delta^{2}(\beta-\gamma)^{4}\left(\Delta-b_{c}\right)^{4}-\delta^{3}(\beta-\gamma)^{6}\left(\Delta-b_{c}\right)^{6}$

$\Omega_{8}=128^{3} \beta^{6} C_{L}^{6} \gamma 4-256^{2} \beta^{5} C_{L}^{5} \delta(\beta-\gamma)\left(\Delta-b_{c}\right)^{2}\left(3 \beta^{2}+22 \beta \gamma-9 \gamma^{2}\right) 4+128^{2} \beta^{4} C_{L}^{4} \delta^{2}(\beta-\gamma)^{3}\left(\Delta-b_{c}\right)^{4}\left(15 \beta^{2}+76 \beta \gamma-15 \gamma^{2}\right)$ $-32^{2} \beta^{3} C_{L}{ }^{3} \delta^{3}(\beta-\gamma)^{5}\left(\Delta-b_{c}\right)^{6}\left(27 \beta^{2}+112 \beta \gamma-15 \gamma^{2}\right)+64 \beta^{2} C_{L}^{2} \delta^{4}(\beta-\gamma)^{7}\left(\Delta-b_{c}\right)^{8}\left(21 \beta^{2}+70 \beta \gamma-15 \gamma^{2}\right)$

$-8 \beta C_{L} \delta^{5}(\beta-\gamma)^{9}\left(\Delta-b_{c}\right)^{10}\left(3 \beta^{2}+5 \beta \gamma-6 \gamma^{2}\right)-\gamma \delta^{6}(\beta+\gamma)(\beta-\gamma)^{11}\left(\Delta-b_{c}\right)^{12}$

$\Omega_{9}=256^{2} \beta^{5} C_{L}^{6}(3 \beta+\gamma) 64-256^{2} \beta^{4} C_{L}^{5} \delta(\beta-\gamma)\left(\Delta-b_{c}\right)^{2}\left(26 \beta^{2}-7 \beta \gamma-5 \gamma^{2}\right) 4+256 \beta^{3} C_{L}^{4} \delta^{2}(\beta-\gamma)^{3}\left(\Delta-b_{c}\right)^{4}\left(80 \beta^{2}-5 \beta \gamma-9 \gamma^{2}\right) 64$ $-512 \beta^{2} C_{L}^{3} \delta^{3}(\beta-\gamma)^{5}\left(\Delta-b_{c}\right)^{6}\left(110 \beta^{2}+3 \beta \gamma-7 \gamma^{2}\right) 2+64 \beta C_{L}^{2} \delta^{4}(\beta-\gamma)^{7}\left(\Delta-b_{c}\right)^{8}\left(65 \beta^{2}-\beta \gamma-2 \gamma^{2}\right)$ $-32 \beta C_{L} \delta^{5}(\beta-\gamma)^{10}\left(\Delta-b_{c}\right)^{10}-\delta^{6}(\beta+\gamma)(\beta-\gamma)^{11}\left(\Delta-b_{c}\right)^{12}$

$\Omega_{10}=256^{2} \beta^{4} C_{L}^{5}(\beta+\gamma) 8-512 \beta^{3} C_{L}^{4} \delta(4 \beta+5 \gamma)(\beta-\gamma)^{2}\left(\Delta-b_{c}\right)^{2} 64+256 \beta^{2} C_{L}^{3} \delta^{2}(4 \beta+9 \gamma)(\beta-\gamma)^{4}\left(\Delta-b_{c}\right)^{4} 8$ $+128 \beta C_{L}^{2} \delta^{3}(2 \beta-7 \gamma)(\beta-\gamma)^{6}\left(\Delta-b_{c}\right)^{6}-8 C_{L} \delta^{4}(5 \beta-2 \gamma)(\beta-\gamma)^{8}\left(\Delta-b_{c}\right)^{8}+\delta^{5}(\beta-\gamma)^{10}\left(\Delta-b_{c}\right)^{10}$

$\Omega_{11}=16^{5} \beta^{5} C_{L}^{5}-32^{3} \beta^{4} C_{L}^{4} \delta(\beta-\gamma)^{2}\left(\Delta-b_{c}\right)^{2} 11+8^{3} \beta^{3} C_{L}^{3} \delta^{2}(\beta-\gamma)^{4}\left(\Delta-b_{c}\right)^{4} 92-64 \beta^{2} C_{L}^{2} \delta^{3}(\beta-\gamma)^{6}\left(\Delta-b_{c}\right)^{6} 46$ $+88 \beta C_{L} \delta^{4}(\beta-\gamma)^{8}\left(\Delta-b_{c}\right)^{8}-\delta^{5}(\beta-\gamma)^{10}\left(\Delta-b_{c}\right)^{10}$ 


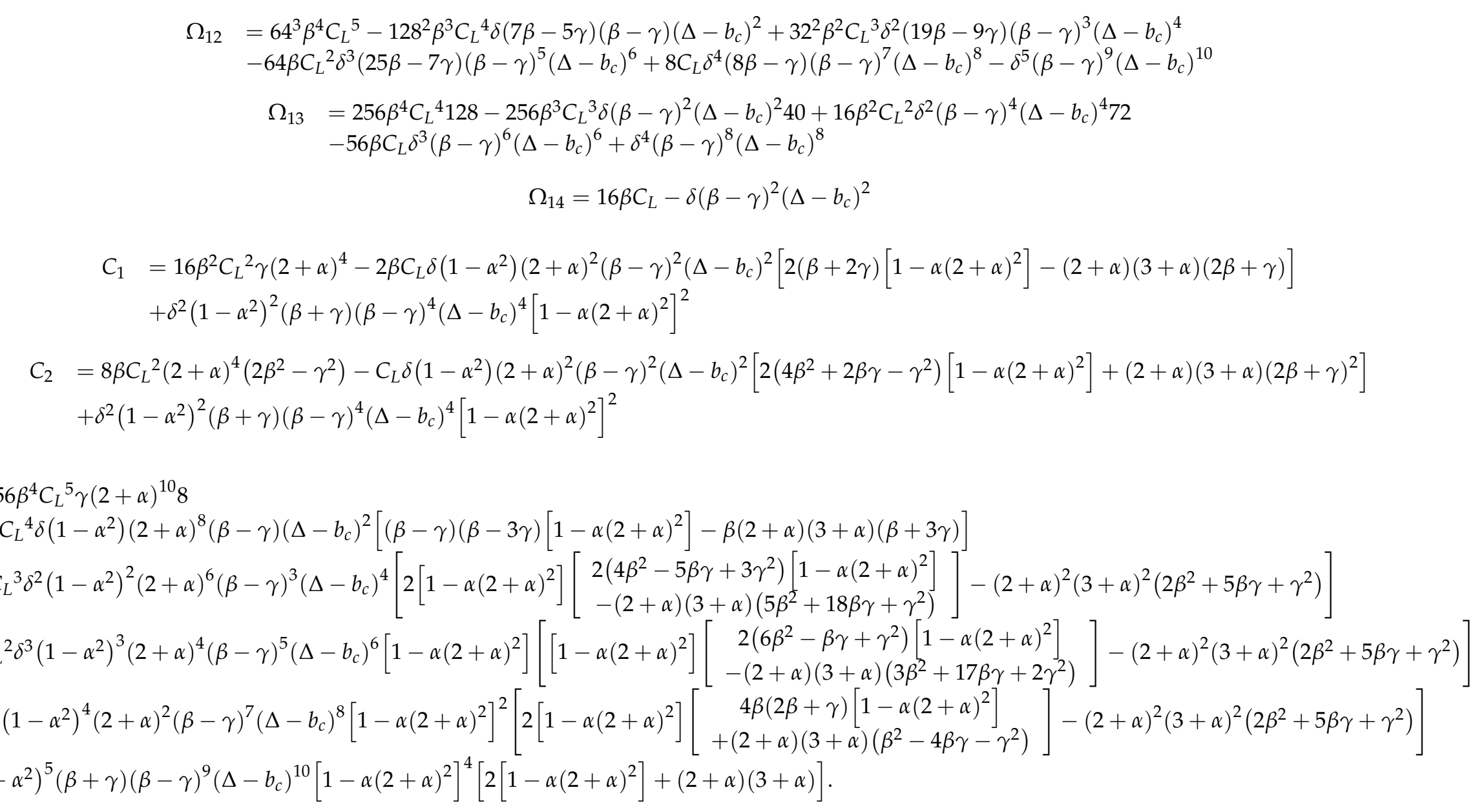




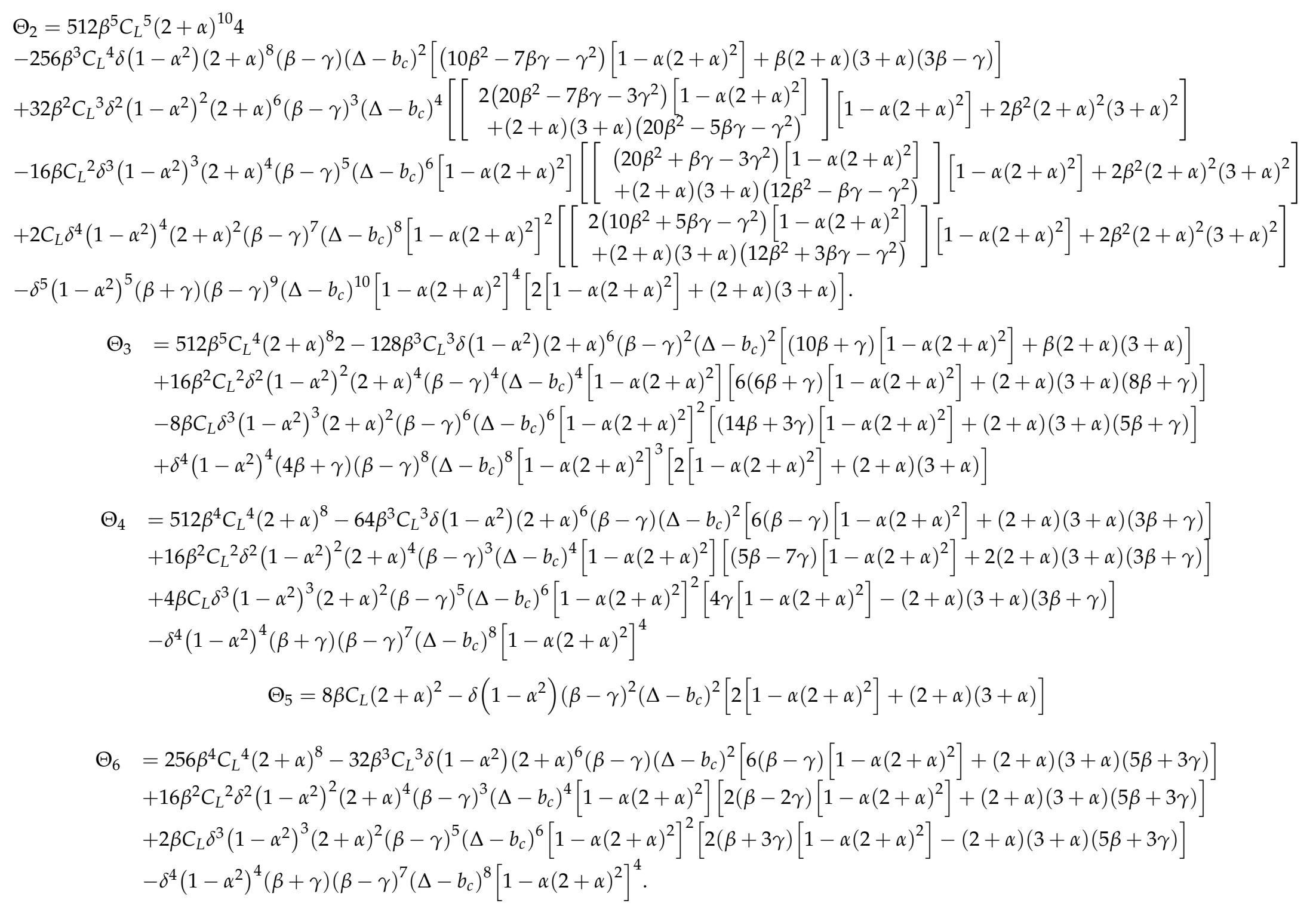




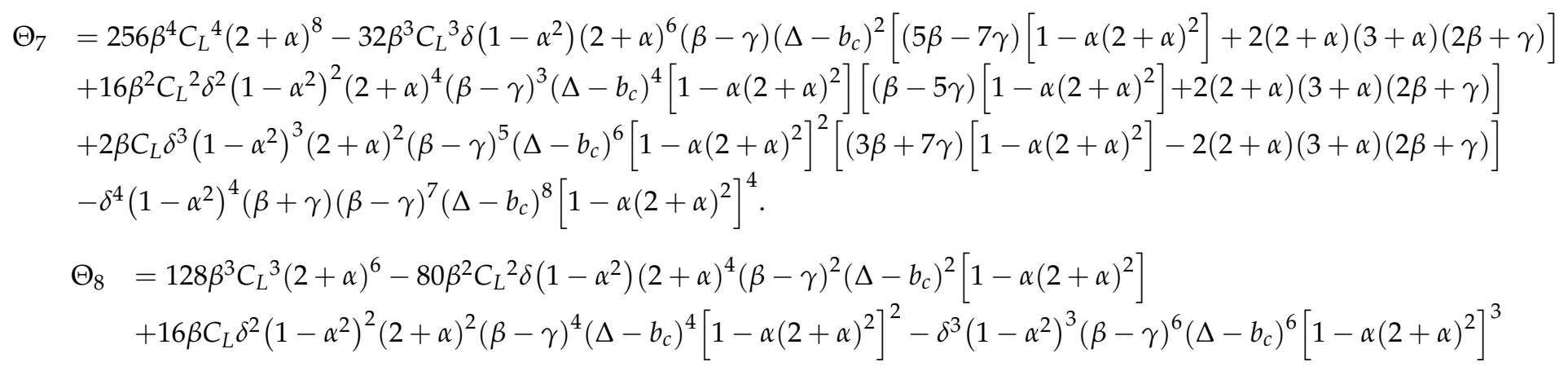

$\Theta_{9}=256 \beta^{6} C_{L}^{6} \gamma(2+\alpha)^{12} 32$

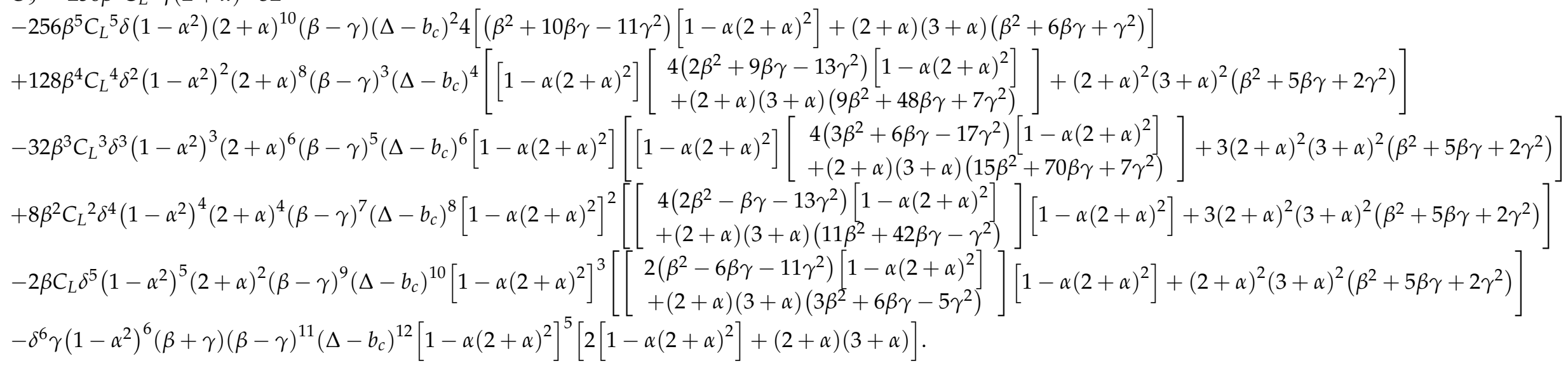


$\Theta_{10}=512 \beta^{5} C_{L}^{6}(2+\alpha)^{12}(3 \beta+\gamma) 8$

$-512 \beta^{4} C_{L}^{5} \delta\left(1-\alpha^{2}\right)(2+\alpha)^{10}(\beta-\gamma)\left(\Delta-b_{c}\right)^{2}\left[2\left(15 \beta^{2}-9 \beta \gamma-4 \gamma^{2}\right)\left[1-\alpha(2+\alpha)^{2}\right]+(2+\alpha)(3+\alpha)\left(11 \beta^{2}+2 \beta \gamma-\gamma^{2}\right)\right]$

$+128 \beta^{3} C_{L}^{4} \delta^{2}\left(1-\alpha^{2}\right)^{2}(2+\alpha)^{8}(\beta-\gamma)^{3}\left(\Delta-b_{c}\right)^{4}\left[\left[\begin{array}{c}4\left(14 \beta^{2}-9 \beta \gamma-3 \gamma^{2}\right)\left[1-\alpha(2+\alpha)^{2}\right. \\ +(2+\alpha)(3+\alpha)\left(44 \beta^{2}+9 \beta \gamma-3 \gamma^{2}\right)\end{array}\right]\left[1-\alpha(2+\alpha)^{2}\right]+2 \beta(2+\alpha)^{2}(3+\alpha)^{2}(2 \beta+\gamma)\right]$

$-32 \beta^{2} C_{L}^{3} \delta^{3}\left(1-\alpha^{2}\right)^{3}(2+\alpha)^{6}(\beta-\gamma)^{5}\left(\Delta-b_{c}\right)^{6}\left[1-\alpha(2+\alpha)^{2}\right]\left[\left[\begin{array}{c}4\left(11 \beta^{2}-11 \beta \gamma-2 \gamma^{2}\right)\left[1-\alpha(2+\alpha)^{2}\right. \\ +(2+\alpha)(3+\alpha)\left(64 \beta^{2}+13 \beta \gamma-3 \gamma^{2}\right)\end{array}\right]\left[1-\alpha(2+\alpha)^{2}\right]+6 \beta(2+\alpha)^{2}(3+\alpha)^{2}(2 \beta+\gamma)\right]$

$+8 \beta C_{L}^{2} \delta^{4}\left(1-\alpha^{2}\right)^{4}(2+\alpha)^{4}(\beta-\gamma)^{7}\left(\Delta-b_{c}\right)^{8}\left[1-\alpha(2+\alpha)^{2}\right]^{2}\left[\left[\begin{array}{c}2\left(3 \beta^{2}-18 \beta \gamma-\gamma^{2}\right)\left[1-\alpha(2+\alpha)^{2}\right. \\ +(2+\alpha)(3+\alpha)\left(38 \beta^{2}+5 \beta \gamma-\gamma^{2}\right)\end{array}\right]\left[1-\alpha(2+\alpha)^{2}\right]+6 \beta(2+\alpha)^{2}(3+\alpha)^{2}(2 \beta+\gamma)\right]$

$+2 \beta C_{L} \delta^{5}\left(1-\alpha^{2}\right)^{5}(2+\alpha)^{2}(\beta-\gamma)^{9}\left(\Delta-b_{c}\right)^{10}\left[1-\alpha(2+\alpha)^{2}\right]^{3}\left[\left[\begin{array}{r}2(5 \beta+9 \gamma)\left[1-\alpha(2+\alpha)^{2}\right] \\ -(2+\alpha)(3+\alpha)(5 \beta-3 \gamma)\end{array}\right]\left[1-\alpha(2+\alpha)^{2}\right]-2(2+\alpha)^{2}(3+\alpha)^{2}(2 \beta+\gamma)\right]$

$-\delta^{6}\left(1-\alpha^{2}\right)^{6}(\beta+\gamma)(\beta-\gamma)^{11}\left(\Delta-b_{c}\right)^{12}\left[1-\alpha(2+\alpha)^{2}\right]^{5}\left[2\left[1-\alpha(2+\alpha)^{2}\right]+(2+\alpha)(3+\alpha)\right]$

$\Theta_{11}=512 \beta^{4} C_{L}^{5}(2+\alpha)^{10}(\beta+\gamma) 4-256 \beta^{3} C_{L}^{4} \delta\left(1-\alpha^{2}\right)(2+\alpha)^{8}(\beta-\gamma)^{2}\left(\Delta-b_{c}\right)^{2}\left[2(3 \beta+4 \gamma)\left[1-\alpha(2+\alpha)^{2}\right]+(2+\alpha)(3+\alpha)(\beta+\gamma)\right]$

$+64 \beta^{2} C_{L}^{3} \delta^{2}\left(1-\alpha^{2}\right)^{2}(2+\alpha)^{6}(\beta-\gamma)^{4}\left(\Delta-b_{c}\right)^{4}\left[1-\alpha(2+\alpha)^{2}\right]\left[4(\beta+3 \gamma)\left[1-\alpha(2+\alpha)^{2}\right]+(2+\alpha)(3+\alpha)(2 \beta+3 \gamma)\right]$

$+16 \beta C_{L}^{2} \delta^{3}\left(1-\alpha^{2}\right)^{3}(2+\alpha)^{4}(\beta-\gamma)^{6}\left(\Delta-b_{c}\right)^{6}\left[1-\alpha(2+\alpha)^{2}\right]^{2}\left[4(\beta-2 \gamma)\left[1-\alpha(2+\alpha)^{2}\right]-3 \gamma(2+\alpha)(3+\alpha)\right]$

$-4 C_{L} \delta^{4}\left(1-\alpha^{2}\right)^{4}(2+\alpha)^{2}(\beta-\gamma)^{8}\left(\Delta-b_{c}\right)^{8}\left[1-\alpha(2+\alpha)^{2}\right]^{3}\left[2(3 \beta-\gamma)\left[1-\alpha(2+\alpha)^{2}\right]+(2+\alpha)(3+\alpha)(2 \beta-\gamma)\right]$

$+\delta^{5} \quad\left(1-\alpha^{2}\right)^{5}(\beta-\gamma)^{10}\left(\Delta-b_{c}\right)^{10}\left[1-\alpha(2+\alpha)^{2}\right]^{4}\left[2\left[1-\alpha(2+\alpha)^{2}\right]+(2+\alpha)(3+\alpha)\right]$.

$$
\Theta_{12}=4 \beta C_{L}(2+\alpha)^{2}-\delta(\beta-\gamma)^{2}\left(1-\alpha^{2}\right)\left(\Delta-b_{c}\right)^{2}\left[1-\alpha(2+\alpha)^{2}\right]
$$

$\Theta_{13}=512 \beta^{5} C_{L}^{5}(2+\alpha)^{10} 8-512 \beta^{4} C_{L}^{4} \delta\left(1-\alpha^{2}\right)(2+\alpha)^{8}(\beta-\gamma)^{2}\left(\Delta-b_{c}\right)^{2}\left[9\left[1-\alpha(2+\alpha)^{2}\right]+(2+\alpha)(3+\alpha)\right]$

$+64 \beta^{3} C_{L}^{3} \delta^{2}\left(1-\alpha^{2}\right)^{2}(2+\alpha)^{6}(\beta-\gamma)^{4}\left(\Delta-b_{c}\right)^{4}\left[1-\alpha(2+\alpha)^{2}\right]\left[32\left[1-\alpha(2+\alpha)^{2}\right]+7(2+\alpha)(3+\alpha)\right]$

$-16 \beta^{2} C_{L}^{2} \delta^{3}\left(1-\alpha^{2}\right)^{3}(2+\alpha)^{4}(\beta-\gamma)^{6}\left(\Delta-b_{c}\right)^{6}\left[1-\alpha(2+\alpha)^{2}\right]^{2}\left[28\left[1-\alpha(2+\alpha)^{2}\right]+9(2+\alpha)(3+\alpha)\right]$

$+4 \beta C_{L} \delta^{4}\left(1-\alpha^{2}\right)^{4}(2+\alpha)^{2}(\beta-\gamma)^{8}\left(\Delta-b_{c}\right)^{8}\left[1-\alpha(2+\alpha)^{2}\right]^{3}\left[12\left[1-\alpha(2+\alpha)^{2}\right]+5(2+\alpha)(3+\alpha)\right]$

$-\delta^{5}\left(1-\alpha^{2}\right)^{5}(\beta-\gamma)^{10}\left(\Delta-b_{c}\right)^{10}\left[1-\alpha(2+\alpha)^{2}\right]^{4}\left[2\left[1-\alpha(2+\alpha)^{2}\right]+(2+\alpha)(3+\alpha)\right]$ 
$\Theta_{14}=512 \beta^{4} C_{L}^{5}(2+\alpha)^{10} 2-128 \beta^{3} C_{L}^{4} \delta\left(1-\alpha^{2}\right)(2+\alpha)^{8}(\beta-\gamma)\left(\Delta-b_{c}\right)^{2}\left[4(3 \beta-2 \gamma)\left[1-\alpha(2+\alpha)^{2}\right]+(2+\alpha)(3+\alpha)(\beta-\gamma)\right]$ $+32 \beta^{2} C_{L}^{3} \delta^{2}\left(1-\alpha^{2}\right)^{2}(2+\alpha)^{6}(\beta-\gamma)^{3}\left(\Delta-b_{c}\right)^{4}\left[1-\alpha(2+\alpha)^{2}\right]\left[4(7 \beta-3 \gamma)\left[1-\alpha(2+\alpha)^{2}\right]+(2+\alpha)(3+\alpha)(5 \beta-3 \gamma)\right]$ $-8 \beta C_{L}^{2} \delta^{3}\left(1-\alpha^{2}\right)^{3}(2+\alpha)^{4}(\beta-\gamma)^{5}\left(\Delta-b_{c}\right)^{6}\left[1-\alpha(2+\alpha)^{2}\right]^{2}\left[8(4 \beta-\gamma)\left[1-\alpha(2+\alpha)^{2}\right]+3(2+\alpha)(3+\alpha)(3 \beta-\gamma)\right]$ $+2 C_{L} \delta^{4}\left(1-\alpha^{2}\right)^{4}(2+\alpha)^{2}(\beta-\gamma)^{7}\left(\Delta-b_{c}\right)^{8}\left[1-\alpha(2+\alpha)^{2}\right]^{3}\left[2(9 \beta-\gamma)\left[1-\alpha(2+\alpha)^{2}\right]+(2+\alpha)(3+\alpha)(7 \beta-\gamma)\right]$ $-\delta^{5}\left(1-\alpha^{2}\right)^{5}(\beta-\gamma)^{9}\left(\Delta-b_{c}\right)^{10}\left[1-\alpha(2+\alpha)^{2}\right]^{4}\left[2\left[1-\alpha(2+\alpha)^{2}\right]+(2+\alpha)(3+\alpha)\right]$

$\Theta_{15}=512 \beta^{4} C_{L}^{4}(2+\alpha)^{8}-64 \beta^{3} C_{L}^{3} \delta\left(1-\alpha^{2}\right)(2+\alpha)^{6}(\beta-\gamma)^{2}\left(\Delta-b_{c}\right)^{2}\left[8\left[1-\alpha(2+\alpha)^{2}\right]+(2+\alpha)(3+\alpha)\right]$ $+48 \beta^{2} C_{L}^{2} \delta^{2}\left(1-\alpha^{2}\right)^{2}(2+\alpha)^{4}(\beta-\gamma)^{4}\left(\Delta-b_{c}\right)^{4}\left[1-\alpha(2+\alpha)^{2}\right]\left[4\left[1-\alpha(2+\alpha)^{2}\right]+(2+\alpha)(3+\alpha)\right]$ $-4 \beta C_{L} \delta^{3}\left(1-\alpha^{2}\right)^{3}(2+\alpha)^{2}(\beta-\gamma)^{6}\left(\Delta-b_{c}\right)^{6}\left[1-\alpha(2+\alpha)^{2}\right]^{2}\left[8\left[1-\alpha(2+\alpha)^{2}\right]+3(2+\alpha)(3+\alpha)\right]$ $+\delta^{4}\left(1-\alpha^{2}\right)^{4}(\beta-\gamma)^{8}\left(\Delta-b_{c}\right)^{8}\left[1-\alpha(2+\alpha)^{2}\right]^{3}\left[2\left[1-\alpha(2+\alpha)^{2}\right]+(2+\alpha)(3+\alpha)\right]$. 


\section{References}

1. Kilic, H.S.; Cebeci, U.; Ayhan, M.B. Reverse logistics system design for the waste of electrical and electronic equipment (WEEE) in Turkey. Resour. Conserv. Recycl. 2015, 95, 120-132. [CrossRef]

2. Özceylan, E.; Paksoy, T. A mixed integer programming model for a closed-loop supply-chain network. Int. J. Prod. Res. 2013, 51, 718-734. [CrossRef]

3. Savaskan, R.C.; Bhattacharya, S.; Wassenhove, L.N.V. Closed-loop supply chain models with product remanufacturing. Manag. Sci. 2004, 50, 239-252. [CrossRef]

4. Savaskan, R.C.; Wassenhove, L.N.V. Reverse channel design: The case of competing retailers. Manag. Sci. 2006, 52, 1-14. [CrossRef]

5. Bhardwaj, V.; Fairhurst, A. Fast fashion: Response to changes in the fashion industry. Int. Rev. Retail. Distr. 2010, 20, 165-173. [CrossRef]

6. Giovanni, P.D. Environmental collaboration through a reverse revenue sharing contract. Ann. Oper. Res. 2011, 6, 1-23.

7. Atasu, A.; Toktay, L.B.; Wassenhove, L.N.V. How collection cost structure drives a manufacturer's reverse channel choice. Prod. Oper. Manag. 2013, 22, 1089-1102. [CrossRef]

8. Saha, S.; Sarmah, S.P.; Moon, I. Dual channel closed-loop supply chain coordination with a reward-driven remanufacturing policy. Int. J. Prod. Res. 2016, 54, 1503-1517. [CrossRef]

9. Han, X.; Wu, H.; Yang, Q.; Shang, J. Collection channel and production decisions in a closed-loop supply chain with remanufacturing cost disruption. Int. J. Prod. Res. 2017, 55, 1147-1167. [CrossRef]

10. Barzinpour, F.; Taki, P. A dual-channel network design model in a green supply chain considering pricing and transportation mode choice. J. Intell. Manuf. 2016, 18, 1-19. [CrossRef]

11. Chiang, W.Y.K.; Chhajed, D.; Hess, J.D. Direct marketing, indirect profits: A strategic analysis of dual-channel supply-chain design. Manag. Sci. 2003, 49, 1-20. [CrossRef]

12. Tsay, A.A.; Agrawal, N. Channel conflict and coordination in the e-commerce age. Prod. Oper. Manag. 2004, 13, 93-110. [CrossRef]

13. Yao, D.; Yue, X.; Wang, X.; Liu, J. The impact of information sharing on a returns policy with the addition of a direct channel. Int. J. Prod. Econ. 2005, 97, 196-209. [CrossRef]

14. Dan, B.; Xu, G.; Liu, C. Pricing policies in a dual-channel supply chain with retail services. Int. J. Prod. Econ. 2012, 139, 312-320. [CrossRef]

15. Xiao, T.; Choi, T.M.; Cheng, T.C.E. Product variety and channel structure strategy for a retailer-Stackelberg supply chain. Eur. J. Oper. Res. 2014, 233, 114-124. [CrossRef]

16. Chen, J.; Zhang, H.; Sun, Y. Implementing coordination contracts in a manufacturer Stackelberg dual-channel supply chain. Omega 2012, 40, 571-583. [CrossRef]

17. Forrester Research Online Retail Forecast, 2014 To 2019. Available online: https://www.forrester.com/report/Forrester+Research+ Online+Retail+Forecast+2014+To+2019+Asia+Pacific/ - /E-RES119284?objectid=RES119284 (accessed on 14 October 2014).

18. $\mathrm{Wu}, \mathrm{X} . ;$ Zhou, Y. The optimal reverse channel choice under supply chain competition. Eur. J. Oper. Res. 2017, 259, 63-66. [CrossRef]

19. Hong, X.; Xu, L.; Du, P.; Wang, W. Joint advertising, pricing and collection decisions in a closed-loop supply chain. Int. J. Prod. Econ. 2015, 167, 12-22. [CrossRef]

20. Miao, Z.W.; Fu, K.; Xia, Z.Q.; Wang, Y. Models for closed-loop supply chain with trade-ins. Omega 2017, 66, 308-326. [CrossRef]

21. Wang, N.; He, Q.; Jiang, B. Hybrid closed-loop supply chains with competition in recycling and product markets. Int. J. Prod. Econ. 2019, 217, 246-258. [CrossRef]

22. Modaka, N.M.; Kazemib, N.; Cárdenas-Barrónc, L.E. Investigating structure of a two-echelon closed-loop supply chain using social work donation as a corporate social responsibility practice. Int. J. Prod. Econ. 2019, 207, 19-33. [CrossRef]

23. Liu, L.; Wang, Z.; Xu, L.; Hong, X.; Govindan, K. Collection effort and reverse channel choices in a closed-loop supply chain. J. Clean. Prod. 2017, 144, 492-500. [CrossRef]

24. Zhao, J.; Wei, J.; Li, M. Collecting channel choice and optimal decisions on pricing and collecting in a remanufacturing supply chain. J. Clean. Prod. 2017, 167, 530-544. [CrossRef]

25. Giovanni, P.D.; Zaccour, G. A two-period game of a closed-loop supply chain. Eur. J. Oper. Res. 2014, 232, 22-40. [CrossRef]

26. Mondal, C.; Giri, B.C. Pricing and used product collection strategies in a two-period closed-loop supply chain under greening level and effort dependent demand. J. Clean. Prod. 2020, 265, 121335. [CrossRef]

27. Lu, Q.; Liu, N. Effects of e-commerce channel entry in a two-echelon supply chain: A comparative analysis of single- and dual-channel distribution systems. Int. J. Prod. Econ. 2015, 165, 100-111. [CrossRef]

28. Zhang, P.; He, Y.; Shi, C. Retailer's channel structure choice: Online channel, offline channel, or dual channels? Int. J. Prod. Econ. 2017, 191, 37-50. [CrossRef]

29. Chen, J.; Liang, L.; Yao, D.; Sun, S. Price and quality decisions in dual-channel supply chains. Eur. J. Oper. Res. 2017, 259, 935-948. [CrossRef]

30. Li, W.; Chen, J.; Liang, G.Q.; Chen, B.T. Money-back guarantee and personalized pricing in a Stackelberg manufacturer's dual-channel supply chain. Int. J. Prod. Econ. 2018, 197, 84-98. [CrossRef] 
31. Saha, S.; Sarmah, S.P.; Modak, N.M. Single versus dual-channel: A strategic analysis in perspective of retailer's profitability under three-level dual-channel supply chain. Asia. Pac. Manag. Rev. 2018, 23, 148-160. [CrossRef]

32. Pun, H.; Chen, J.; Li, W. Channel strategy for manufacturers in the presence of service freeriders. Eur. J. Oper. Res. 2020, 287, 460-479. [CrossRef]

33. He, R.; Xiong, Y.; Lin, Z. Carbon emissions in a dual channel closed-loop supply chain: The impact of consumer free riding behavior. J. Clean. Prod. 2016, 134, 384-394. [CrossRef]

34. Batarfi, R.; Jaber, M.Y.; Aljazzar, S.M. A profit maximization for a reverse logistics dual-channel supply chain with a return policy. Comput. Ind. Eng. 2017, 106, 58-82. [CrossRef]

35. Taleizadeh, A.A.; Moshtagh, M.S.; Moon, I. Pricing, product quality, and collection optimization in a decentralized closed-loop supply chain with different channel structures: Game theoretical approach. J. Clean. Prod. 2018, 189, 406-431. [CrossRef]

36. He, P.; He, Y.; Xu, H. Channel structure and pricing in a dual-channel closed-loop supply chain with government subsidy. Int. J. Prod. Econ. 2019, 213, 108-123. [CrossRef]

37. Xiao, L.; Wang, X.J.; Chin, K.S. Trade-in strategies in retail channel and dual-channel closed-loop supply chain with remanufacturing. Transp. Res. E Logist. Transp. Rev. 2020, 136, 101898. [CrossRef]

38. Shi, T.Q.; Chhajed, D.; Wan, Z.X.; Liu, Y.C. Distribution channel choice and divisional conflict in remanufacturing operations. Prod. Oper. Manag. 2020, 29, 1702-1719. [CrossRef]

39. Li, H.; Wang, C.; Xu, L.; Ou, W. Emission reduction, pricing and collection decisions and coordination in low-carbon closed-loop supply chain with hybrid collecting channel. Bol. Tech. 2017, 55, 233-247.

40. Tayur, S.; Ganeshan, R.; Magazine, M. Quantitative Models for Supply Chain Management; Kluwer Academic Publishers: Boston, MA, USA, 1998.

41. Tadelis, S. Game Theory: An Introduction; Princeton University Press: Princeton, NJ, USA, 2013.

42. Xie, S.Y. Economic Game Theory; Fudan University Press: Shanghai, China, 2014.

43. Huang, M.; Song, M.; Lee, L.H.W.; Ching, K. Analysis for strategy of closed-loop supply chain with dual recycling channel. Int. J. Prod. Econ. 2013, 144, 510-520. [CrossRef]

44. Wei, J.; Zhao, J.; Li, Y. Pricing decisions for complementary products with firms' different market powers. Eur. J. Oper. Res. 2013, 224, 507-519. [CrossRef]

45. Batarfi, R.; Jaber, M.Y.; Zanoni, S. Dual-channel supply chain: A strategy to maximize profit. Appl. Math. Model. 2016, 40, 9454-9473. [CrossRef]

46. Hong, X.; Wang, Z.; Wang, D.; Zhang, H. Decision models of closed-loop supply chain with remanufacturing under hybrid dual-channel collection. Int. J. Adv. Manuf. Technol. 2013, 68, 1851-1865. [CrossRef]

47. Zhao, J.; Hou, X.; Guo, Y.; Wei, J. Pricing policies for complementary products in a dual-channel supply chain. Appl. Math. Model. 2017, 49, 437-451. [CrossRef] 